WORKING PAPER

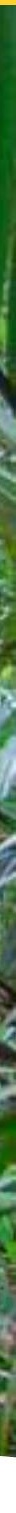

\title{
Protocols for the measurement, monitoring and reporting of structure, biomass and carbon stocks in mangrove forests
}

J. Boone Kauffman

Daniel C. Donato

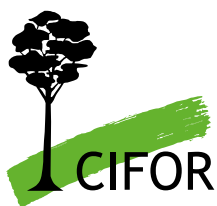



Working Paper 86

\title{
Protocols for the measurement, monitoring and reporting of structure, biomass and carbon stocks in mangrove forests
}

\author{
J. Boone Kauffman \\ Department of Fisheries and Wildlife, Oregon State University and CIFOR \\ Daniel C. Donato \\ Ecosystem \& Landscape Ecology Lab, University of Wisconsin and College of Forestry, Oregon State University
}


Working Paper 86

(c) 2012 Center for International Forestry Research

All rights reserved

Kauffman, J.B. and Donato, D.C. 2012 Protocols for the measurement, monitoring and reporting of structure, biomass and carbon stocks in mangrove forests. Working Paper 86. CIFOR, Bogor, Indonesia.

Cover photo by Daniel Murdiyarso

\section{CIFOR}

Jl. CIFOR, Situ Gede

Bogor Barat 16115

Indonesia

$\mathrm{T}+62(251) 8622-622$

$\mathrm{F}+62(251) 8622-100$

E cifor@cgiar.org

\section{www.cifor.org}

Any views expressed in this publication are those of the authors. They do not necessarily represent the views of CIFOR, the authors' institutions or the financial sponsors of this publication. 


\section{Table of contents}

Abbreviations $\quad$ v

Acknowledgments

1 Introduction 1

1.1 Purpose and scope 3

1.2 Essential sources of information 4

1.3 Conceptual basis 4

2 Field procedures $\quad 10$

2.1 Unique considerations for measuring carbon in mangroves 11

2.2 General information to be collected at each plot 11

2.3 Specific measurements in plots and subplots 12

3 Laboratory and data analysis $\quad 21$

$\begin{array}{lll}3.1 \text { Biomass and carbon pools of vegetation } & 21\end{array}$

3.2 Total carbon stock or the total ecosystem carbon pool 30

3.3 Quantifying uncertainty in carbon pools 30

4 Reporting 33

5 References $\quad 37$ 


\section{List of figures and tables}

\section{Figures}

1 Different mangrove species

2 Large pneumatophores of a Sonneratia alba tree, Runuuw, Yap, FSM

3 Total ecosystem carbon pools (aboveground and belowground) for some major land cover types of the world

4 The ecosystem components of mangroves for the quantification of forest biomass and ecosystem carbon stocks

5 Suggested steps in the preparation of a carbon stock/emissions measurement plan

7 Examples of clustered plot designs used in different forest inventories

8 The plot layout for carbon stock sampling of mangroves within the Sundarbans Reserve Forest, Bangladesh

9 A recommend plot layout to measure carbon stocks, composition and structure of dwarf mangrove communities (mangle chaparro)

10 An example of a systematic sampling grid from the Sundarbans, Bangladesh.

11 The cycle of tides and the 'Rule of Twelfths' that influence the optimal times to sample vegetation and soils in mangrove ecosystems.

12 Measuring tree diameter at breast height

13 The dead tree decay status classes for tropical trees.

14 The field measurement techniques for determining biomass of dwarf mangroves. $\quad 14$

15 Schematic of densiometer mirror, with the four dots depicted in each square 15

16 The accumulation of dead and downed wood in a mangrove ecosystem following a severe typhoon

17 Example of a wood debris transect for sampling downed wood in mangroves using the line intersect technique (also referred to as the planar intercept technique) 17

18 Example of a downed wood transect in a mangrove (left), and measurements of different downed wood size-classes (right)

19 A step by step photos series of the collection of soil samples from an open-face (peat) auger

20 Comparison of tree biomass estimates for Burguiera gymnorrhiza and Sonneratia alba

21 The relationship between organic matter (calculated via loss on ignition) and carbon concentration (percentage) (calculated via dry combustion) for mangrove soil samples from the Republic of Palau

22 Ecosystem carbon pools of selected mangroves of the Indo-Pacific region 35

23 Representative photos of different mangrove forests

\section{Tables}

1 Tiers that may be used to assess carbon emission factors 5

2 Commonly used size classes of wood, based on the timelag constant 17

3 Allometric equations for computing biomass of mangrove trees, where only parameters of diameter and wood density are used

4 Allometric equations using tree height and diameter for computing biomass of mangrove trees

5 Examples of wood density for common mangrove species

6 The specific gravity and mean diameter of the standard wood debris size classes of downed mangrove wood used to estimate wood mass

7 Downed wood mass (Mg ha-1) by size class (diameter in $\mathrm{cm}$ ) and condition in mangrove forests, Yap, FSM

8 Examples of carbon pools divided into discrete components of the ecosystem 


\section{Abbreviations}

CI confidence interval

dbh diameter at breast height

FSM Federated States of Micronesia

IPCC Intergovernmental Panel on Climate Change

LOI loss on ignition

REDD+ Reducing Emissions from Deforestation and Forest Degradation, and Enhancing Forest Carbon Stocks in Developing Countries

SE standard error 


\section{Acknowledgments}

The two authors made an equal contribution to this paper, which was made possible through grants from the US Forest Service International Programs, the US Agency for International Development (USAID), and the US State Department. We are grateful to Melanie Stidham and Daniel Murdiyarso for their contributions to development of this paper. We also wish to thank Elizabeth Lebow and Cynthia Mackie for contributions to the conceptualisation of this paper, and Jeff Gove and Kathleen Dwire for early reviews. We also thank Jeff Merriam for the analysis of the LOI of soil samples. Finally, we wish to thank the many field technicians from throughout the tropics who assisted in field methods development. 


\section{Introduction}

Mangroves are defined as an association of halophytic trees, shrubs and other plants growing in brackish to saline tidal waters of tropical and subtropical coastlines (Mitsch and Gosselink 2007). Mangroves are generally restricted to the tidal zone. As such, mangroves in fringe areas will be inundated by practically all high tides, while those at the higher topographic boundaries may be flooded only during the highest of tides (spring tides) or during storm surges. Mangroves are typically found along tropical and subtropical coastlines between about $25^{\circ} \mathrm{N}$ and $25^{\circ} \mathrm{S}$.

Globally, there are at least 68 mangrove-obligate species. The centre of diversity of mangroves is the Indo-Pacific region where Giesen et al. (2007) listed 52 plant species that occurred only in mangroves and 268 species that can be found in mangroves and other wet environments. In contrast, the Americas have only about 10 mangrove species (Mitch and Gosselink 2007).

Mangroves vary greatly in structure and function, largely as a result of topography, substrate, latitude and hydrology (Saenger and Snedaker 1993). Dominants in mature mangroves may range from trees with trunk diameters $>1 \mathrm{~m}$ to shrub-like stands
$<1 \mathrm{~m}$ in height (Figure 1). Aboveground biomass may range from $>500 \mathrm{Mg} /$ ha in riverine and fringe mangroves of the Indo-Pacific region to about 8 $\mathrm{Mg} / \mathrm{ha}$ for dwarf mangroves (Kauffman and Cole 2010, Kauffman et al. 2011). Mangroves have been classified into four major associations of differing structure, corresponding to physical, climatic and hydrologic features of the environment in which they exist. These are 1) fringe or coastal mangroves; 2) riverine or estuarine mangroves; 3 ) basin mangroves; and 4) dwarf or scrub (or chaparro) mangroves (Cintron et al. 1978, Mitch and Gosselink 2007).

Mangroves exist in saline or brackish wetland environments that often consist of anoxic (highly reduced) sediments, and are subject to severe tropical cyclones. As such, mangrove species possess a number of unique adaptations to facilitate survival in this environment. Most notably this includes stilt roots and pneumatophores (Figure 2) to allow gaseous exchange for root tissues. In response to canopy disturbances, some species resprout and others rapidly seed in order to fill available growing spaces (e.g. Kauffman and Cole 2010).

Estimates of the worldwide extent of mangroves range from 14 to 24 million ha. The most recent
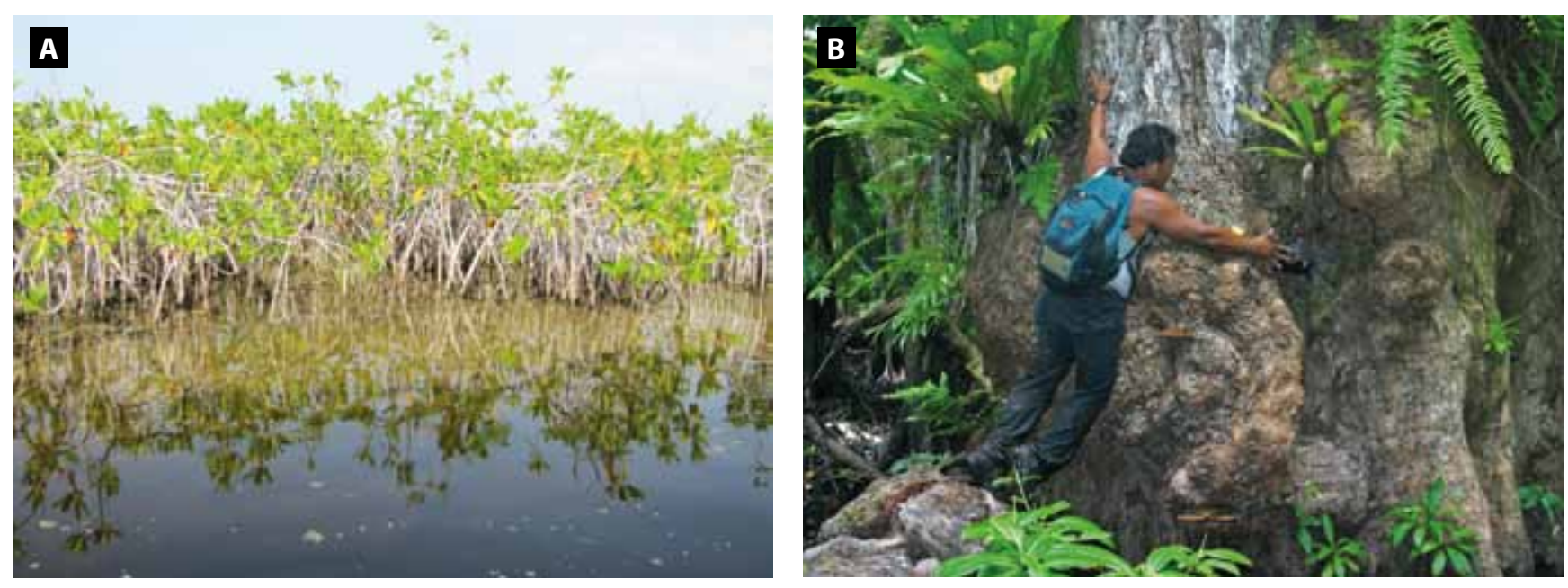

Figure 1. Different mangrove species (Photos by J.B. Kauffman/Oregon State University)

Notes: A) A dwarf mangrove ecosystem (mangle chaparro), Sian Ka'an Biosphere Reserve, Quintana Roo, Mexico. B) A large Sonneratia alba tree, Yela River Mangrove Forest, Kosrae, Federated States of Micronesia (FSM). The differences between these two mangroves in terms of structure, function and composition are dramatic, yet both provide significant ecosystem services including water quality regulation, storm protection, fisheries production and wildlife habitat. 


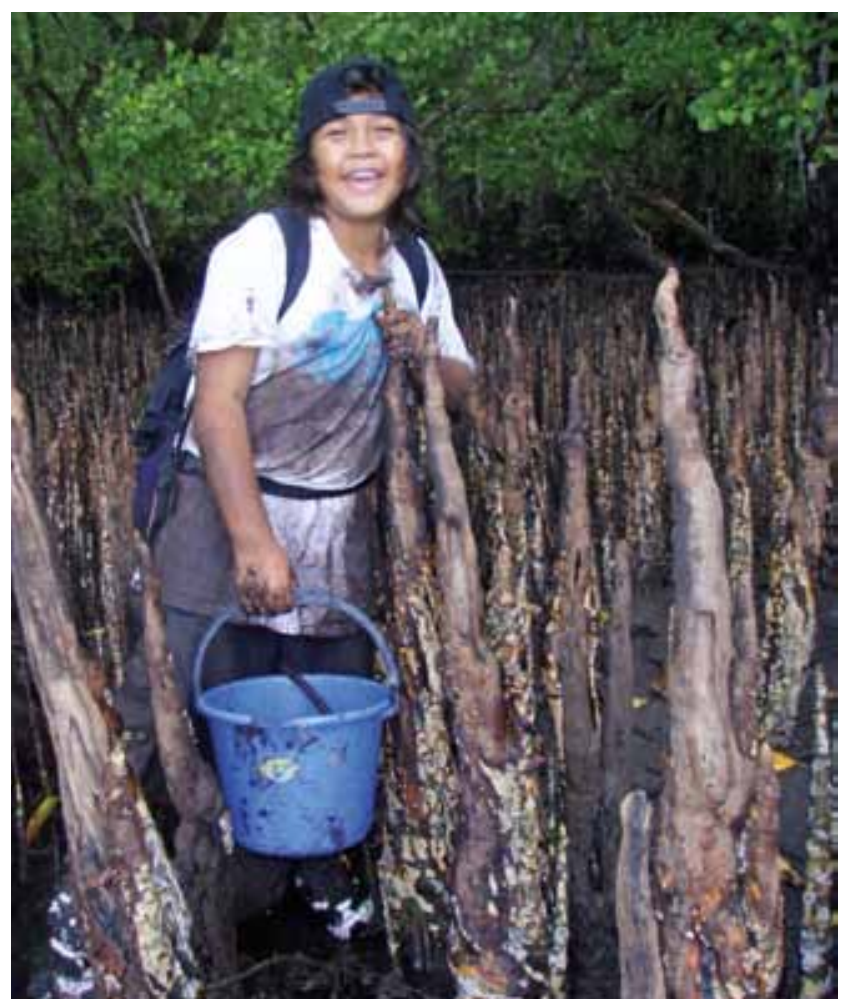

Figure 2. Large pneumatophores of a Sonneratia alba tree, Runuuw, Yap, FSM (Photo by J.B. Kauffman/Oregon State University)

estimates suggest the current value is near the low end of this range (Giri et al. 2010), which may reflect both improved estimation techniques and/or losses associated with deforestation and conversion of mangroves. Asia supports the world's largest mangrove areas, originally extending over 6.8 million ha and representing $34-42 \%$ of the world's total (Indonesia alone contains almost $23 \%$ of the world's mangroves). This is followed by Africa (20\%), North and Central America (15\%), Oceania (12\%), South America (11\%), and Australia (7\%) (Giri et al. 2011). Southeast Asian mangroves are the best developed and probably the most species-diverse in the world (Giesen et al. 2007). Four countries (Indonesia, Brazil, Australia and Mexico) account for about $42 \%$ of all mangroves, and $64 \%$ of the total mangrove area is found in just 10 countries (Giri et al. 2011).

Mangroves are keystone coastal ecosystems providing numerous environmental services and critical ecological functions, affecting both upland and oceanic resources. These values include protection from storms and tsunamis (Giesen et al. 2007, Mitch and Gosselink 2007, Alongi 2009), regulation of water quality, breeding and rearing habitats for many species of fish and shellfish, important sources of wood and other forest products for local populations, and biodiversity, including habitats for many rare and endangered species (Duke et al. 2007, FAO 2007). These ecosystems are a source of nutrients and energy for adjacent habitats including seagrass and coral reefs, and are also valued for aesthetics and ecotourism. As much as $75 \%$ of all tropical commercial fish species spend part of their lifecycle in mangroves. Mangroves have been used for centuries by indigenous peoples for wood, thatch, medicines, dyes, and fish and shellfish. Mangrove forests are also among the major carbon sinks of the tropics (Cahoon et al. 2003, Bouillon et al. 2008, Nellemann et al. 2009) (Figure 3).

Perhaps the least investigated, yet critically important, ecosystem service of mangroves is that of carbon storage. Mangrove carbon pools are among the highest of any forest type (Figure 3). For example, ecosystem carbon pools of mangroves in the Indo-Pacific region are more than twice those of most upland tropical and temperate forests. A great proportion of this pool is belowground in organicrich soils which are highly susceptible to releasing significant volumes of greenhouse gases if disturbed

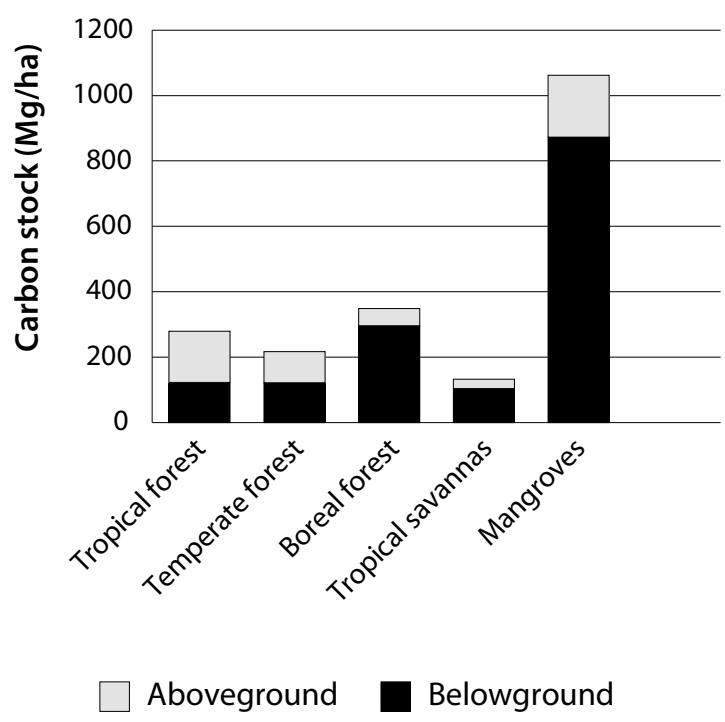

Figure 3. Total ecosystem carbon pools (aboveground and belowground) for some major land cover types of the world

Source: Data for all forests, except mangroves are from IPCC (2001) and Laffoley and Grimsditch (2009). Mangrove forests are those of the Asia-Pacific region (Donato et al. 2011, Kauffman et al. 2011) 
by land-use or climate change (Page et al. 2010, Hooijer et al. 2006).

Mangrove forests are threatened by land-use and/or land-cover change, as well as global climate change. Rates of mangrove deforestation and conversion are among the highest of all tropical forests, far exceeding rates in upland forests (Valiela et al. 2001, Langner $e t$ al. 2007). Land conversion has resulted in the loss of more than $35 \%$ of mangroves during 1980-2000 (Valiela et al. 2001, Giesen et al. 2007). Global climate change impacts that may exacerbate losses include sea-level rise, changes in tropical storm (cyclone) intensity, and changes in stream flows that discharge into mangroves (Gilman et al. 2008).

Because of the values of, and threats to, mangroves, surveys to describe forest composition, structure and ecosystem carbon pools are needed to monitor status and trends. Of great interest is mangroves' potential value in carbon mitigation programmes, such as Reducing Emissions from Deforestation and Forest Degradation, and Enhancing Forest Carbon Stocks in Developing Countries (REDD+), and other financial incentives tied to conservation of standing forests. REDD+ is a mechanism to reduce global greenhouse gases by compensating countries for avoiding deforestation or forest degradation. In addition, REDD+ entails a broader framework that could include compensation for forest conservation, sustainable forest management, or enhancement of carbon stocks. Because of their large ecosystem carbon stocks, as well as the numerous other critical ecosystem services they provide, mangroves are potentially well suited to these climate change mitigation strategies.

Mangroves are quite different from upland forests in both composition and structure. The presence of stilt roots or pneumatophores is an obvious difference. In addition, understory vegetation and a well-developed floor litter are usually absent (crabs are usually extremely efficient consumers of fallen leaves in mangroves). Because of numerous differences in the structure and environment of mangroves compared to upland forests, approaches to quantifying their composition, structure, carbon stocks and status are different. While numerous examples exist of approaches to sampling upland forests, this report fills a gap in describing approaches to the measurement, monitoring and reporting of the composition, structure and carbon stocks of mangrove ecosystems. Especially important for mangroves is the sampling of belowground pools that often consist of large stores of carbon in peats, mucks and sediments (Donato et al. 2011, Kauffman et al. 2011).

\subsection{Purpose and scope}

The purpose of this report is provide ideas and approaches to accurately measure, monitor and report species composition and structure, aboveground biomass, and carbon stocks of mangrove ecosystems. We outline the rationale, design, field measurements, analysis and reporting for carbon assessments in mangrove ecosystems. While the focus is on mangroves, the approaches generally apply to other wetland forests as well. A number of methods are suitable for measuring forest carbon stocks, but the focus here is on consistency with international standards outlined in the guidelines of the Intergovernmental Panel on Climate Change (IPCC) and relevant sourcebooks. The aim is to provide information on field measurements and computations that will support entry into regulatory or voluntary carbon markets. We do not address less direct measurement approaches such as using biomass expansion factors and stand density indexes. Rather, we focus on improving and making available methods based on field measurements that use allometric equations for biomass estimates.

The technical aspect of quantifying forest carbon is only one of several elements of carbon accounting schemes. Other important elements include social, political and economic factors - for example, addressing permanence, leakage and governance, etc. - but these are not covered here. Definitions and information on those topics can be found in the IPCC guidelines (IPCC 2007) and associated sourcebooks (e.g. GOFC-GOLD 2011).

This document aims to provide a general conceptual background, as well as specific instructions for the collection and analysis of biometric data in mangroves. Specific recommendations for overall sampling design, plot layout and measurements are provided based on the authors' experience in measuring forest structure and carbon pools of mangroves in the Indo-Pacific region and Mexico. Other approaches, with differing plot shape, plot size, sample size, allometric equations and statistical analyses may also be adequate. Project personnel may choose to adapt specific methods according to their local knowledge, training, resource constraints, other 


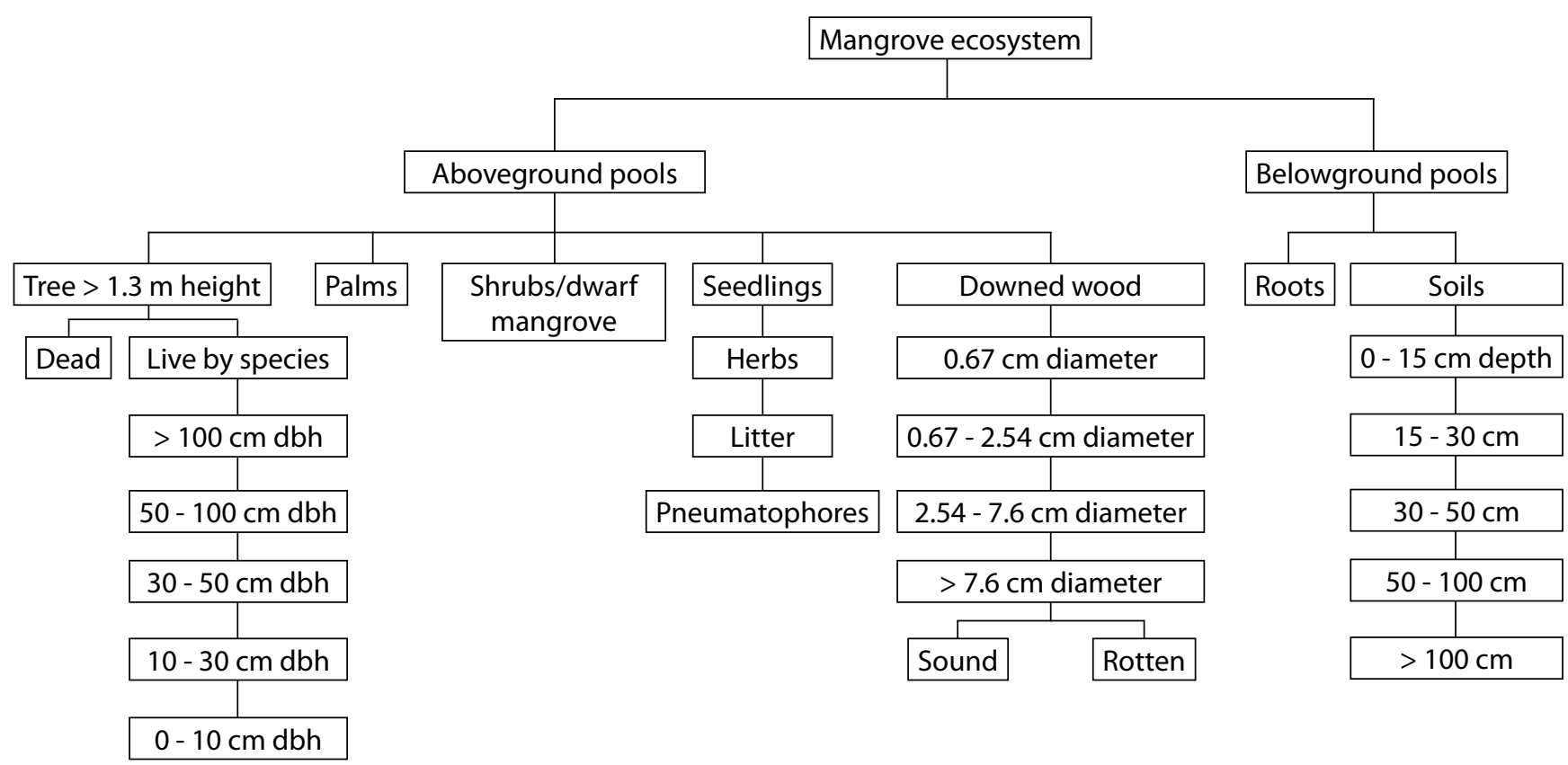

Figure 4. The ecosystem components of mangroves for the quantification of forest biomass and ecosystem carbon stocks.

$\mathrm{dbh}=$ diameter at breast height.

data collection needs or the evolving nature of the IPCC and related sourcebook guidelines.

\subsection{Essential sources of information}

The approaches described here are particularly relevant to monitoring, reporting and verification in mangroves as part of restoration, adaptation or mitigation projects. Mitigation would include carbon financing programmes such as REDD+. Approaches to upland forest sampling may provide guidance in project implementation and design. Some of these guidelines cover information relating to carbon financing and carbon markets, which are beyond the scope of this paper. Notable examples include IPCC $(2003,2006)$, Pearson et al. (2005, 2007) and GOFC-GOLD (2011). For information on the establishment of permanent plots and related sampling methods, the Center for Tropical Forest Science ${ }^{1}$ and the Amazon Forest Inventory Network ${ }^{2}$ are recommended. Information on allometric equations in the analysis of mangrove forest tree biomass has been reviewed in Komiyama et al. (2008) and Saenger (2002).

1 http://www.ctfs.si.edu/group/Resources/Methods

2 http://www.geog.leeds.ac.uk/projects/rainfor/

\subsection{Conceptual basis}

\subsubsection{Tracking carbon stocks, deforestation and forest degradation}

Carbon stocks are the combined storage of carbon in terrestrial ecosystems (GOFC-GOLD 2011. In simplified terms, forest carbon accounting tracks changes in carbon stocks due to land-use and landcover change: deforestation, degradation, conversion, afforestation etc. In order to quantify carbon stocks of mangroves, the ecosystems are conceptually subdivided into components that can be accurately measured using specific techniques for each pool (Figure 4). One important division is aboveground and belowground components. Some pools are more critical than others to obtaining accurate estimates of forest biomass and ecosystem carbon stocks. Carbon stocks can also be subdivided on the basis of susceptibility to loss by land-use or landcover change. Generally, carbon pools vulnerable to these changes are aboveground biomass and belowground pools to $30 \mathrm{~cm}$. However, in wetland organic soils, the entire belowground pool may be susceptible to loss via tidal and storm surges as well as decomposition following land-cover change. 


\subsubsection{Data types}

Carbon inventorying requires two data types: activity data and emission factors. Activity data refers to the landscape coverage of different land uses, such as forest, agricultural land, grassland or settlements, and the degree of transfer between them. Activity data usually relies heavily on remote sensing analyses to classify land-use types and to track changes between land uses over time. Emission factors refer to changes in various carbon pools of a forest. Changes may occur due to conversion between different land uses (e.g. from forest cover to agricultural land), or due to changes within a land-use type (e.g. forest degradation due to selective logging). Accurate quantification of emission factors requires groundbased measurements of ecosystem carbon stocks. Such methods are described in detail in this report.

\subsubsection{Tiers of assessment}

For participation in REDD+ programmes, the IPCC has established a tier system reflecting the degrees of certainty or accuracy of the carbon stock assessment (Table 1). Tier 1 uses IPCC default values (i.e. biomass in different forest biomes, etc.) and simplified assumptions; it may have an error range of $+/-50 \%$ for aboveground pools and $+/-90 \%$ for the variable soil carbon pool. Tier 2 requires countryspecific carbon data for key factors. Tier 3 requires highly specific inventory-type data on carbon stocks in different pools, and repeated measurements of key carbon stocks through time, which may also be supported by modelling. The methods reported here are relevant to achieving a Tier 3 assessment of carbon stocks.

The IPCC recommends that countries aspire to Tier 3 where possible for the measurement of key carbon stocks, sources and sinks. Tiers 2 and 3 produce more credible estimates and may support higher rates of carbon payment. On the other hand, Tier 3 is more costly to implement and is not always possible.

\section{Table 1. Tiers that may be used to assess carbon} emission factors

\begin{tabular}{|c|c|}
\hline Tier & Requirements \\
\hline 1 & IPCC default factors \\
\hline 2 & Country-specific data for key factors \\
\hline 3 & $\begin{array}{l}\text { Detailed inventory of key carbon stocks, } \\
\text { repeated measurements of key stocks through } \\
\text { time or modelling }\end{array}$ \\
\hline
\end{tabular}

Source: Adapted from GOFC-GOLD (2011)
Forest inventories or forest carbon assessments are conducted to determine forest carbon stocks at one point in time. These are then repeated to quantify increases or decreases through time, thus determining if the forest in question is a net source or sink of carbon. Two approaches to this estimation are the stock-change approach and the gain-loss approach (GOFC-GOLD 2011 ). The stock-change approach estimates the difference in carbon stocks at two points in time, while the gain-loss approach estimates the net balance of additions to and removals from a carbon stock.

The stock-change approach is used when carbon stocks in relevant pools have been measured and estimated over time, such as in forest inventories. Thus, Tier 3 assessments often use stockchange methods.

The gain-loss approach is used when annual data, such as biomass growth rates and reliable data on wood harvests, are available. This approach is more often used in Tier 1 and Tier 2 assessments. However, a mix of the two approaches may be part of any assessment.

\subsubsection{Developing a measurement plan}

The steps to preparing a robust measurement plan are summarized in Figure 5. Each of these steps should be carried out in a transparent, consistent, welljustified manner.

Details of each step in preparing a management plan are described below.

\section{Step 1: Define the project area boundaries}

The definition of area boundaries will depend on the scope and objectives of the project or study. Project areas may range from a single mangrove forest to national-scale assessments. If the objective is a broadscale assessment, an approach that adequately samples a representative range of mangrove types should be implemented.

The project area for a mangrove assessment should be restricted to lands either currently or historically occupied by mangrove ecosystems. Care should be taken not to include adjacent marine, upland or freshwater ecosystems as part of the assessment. 


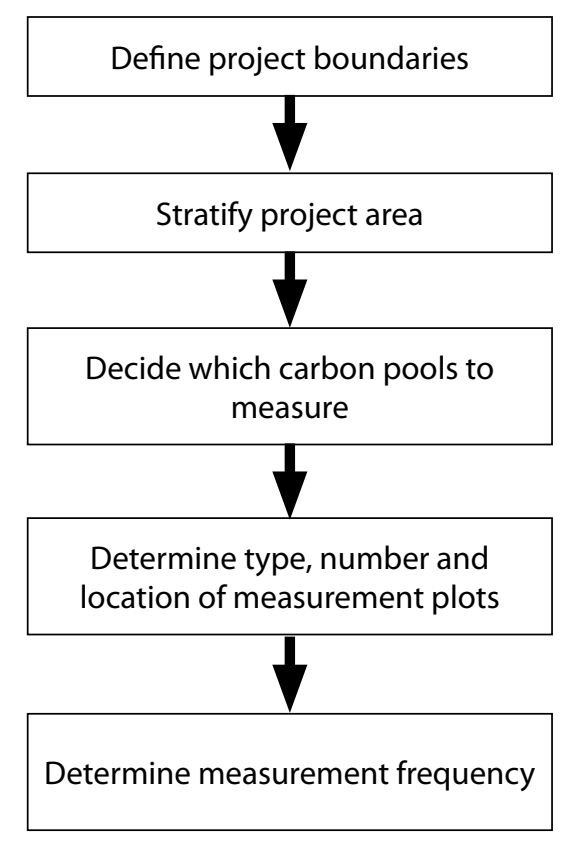

Figure 5. Suggested steps in the preparation of a carbon stock/emissions measurement plan.

Source: Pearson et al. (2005)

\section{Step 2: Decide on stratification of the project area} Within project area boundaries, it is not uncommon to encounter differences in mangrove composition and structure (Figure 1). Mangroves may be composed of a mosaic of tall forest, dwarf mangrove and even nipa palm (Nypa fruticans). In such cases it may be desirable to stratify the project area into subpopulations, sections that form relatively homogenous units. Following stratification, some plots should be sampled in each type. Because within-stratum variation will be lower, fewer plots may be needed to achieve an acceptable level of precision. Useful tools for defining strata include ground-truthed maps from satellite imagery; aerial photographs; maps of vegetation, soils or topography; and experience. To characterise shoreline-to-upland gradients, it may also be desirable to sample different distances from the seaward edge of a mangrove forest, as soil depths, tree composition, and therefore carbon pools can vary with slight changes in relative elevation and tidal influence along this gradient (Kauffman et al. 2011).

\section{Step 3: Decide which carbon pools to measure}

Similar to most forest types, mangroves can be roughly divided into five carbon pools: 1 ) aboveground biomass of live vegetation; 2) belowground biomass of live vegetation; 3) dead wood; 4) forest floor (litter); and 5) soil. A pool should be measured if it is: (1) large; (2) if it is likely to be affected by land use; (3) if the future land-uses are uncertain; and (4) if the pool size is uncertain. Small pools or those unlikely to be affected by land use change may be excluded or sampled less frequently. In mangroves, non-tree vegetation and litter are usually minor ecosystem components and can often be excluded from measurements without compromising the accuracy of the sample.

Trees are always included since they are relatively easy to measure, good scaling equations exist, and they are heavily affected by land use. Dead wood is often an important pool in mangroves, especially following disturbances such as land-use change or tropical storms (Kauffman and Cole 2010). Many mangroves have deep organic-rich soils (peat) resulting in large carbon pools. The large size of these belowground pools and their poorly understood vulnerability to land-use change makes their measurement relatively important.

\section{Step 4: Determine type, number and location of} measurement plots

Type. Whether plots are temporary or permanent depends on the purpose of the study. Permanent plots are usually established for the purpose of repeated measurements. Typically, in permanent plots, the boundaries are clearly marked and all trees within plots are mapped and/or tagged (usually with aluminium tags). Downed wood and other vegetation components may also be marked or tagged. Pearson et al. $(2005,2007)$ provide valuable reviews on approaches to monitoring calculations using tagged trees. In temporary plots, trees are not tagged. Usually, the objectives are for a single measurement of forest composition, structure and/ or carbon pools. Permanent plots have greater longterm value and credibility in determining carbon stock changes through time. Examples of potential permanent plot designs suitable for mangroves can be found in figures $6,7,8$, and 9 .

Figure 6 illustrates the plot layout for mangroves sampled in the Indo-Pacific Forest Carbon study (Donato et. al. 2011); and the Tropical Wetlands Initiative for Climate Change Adaptation and Mitigation (J. Boone Kauffman and Daniel Murdiyarso, personal communication). In this design, circular plots are established perpendicular 


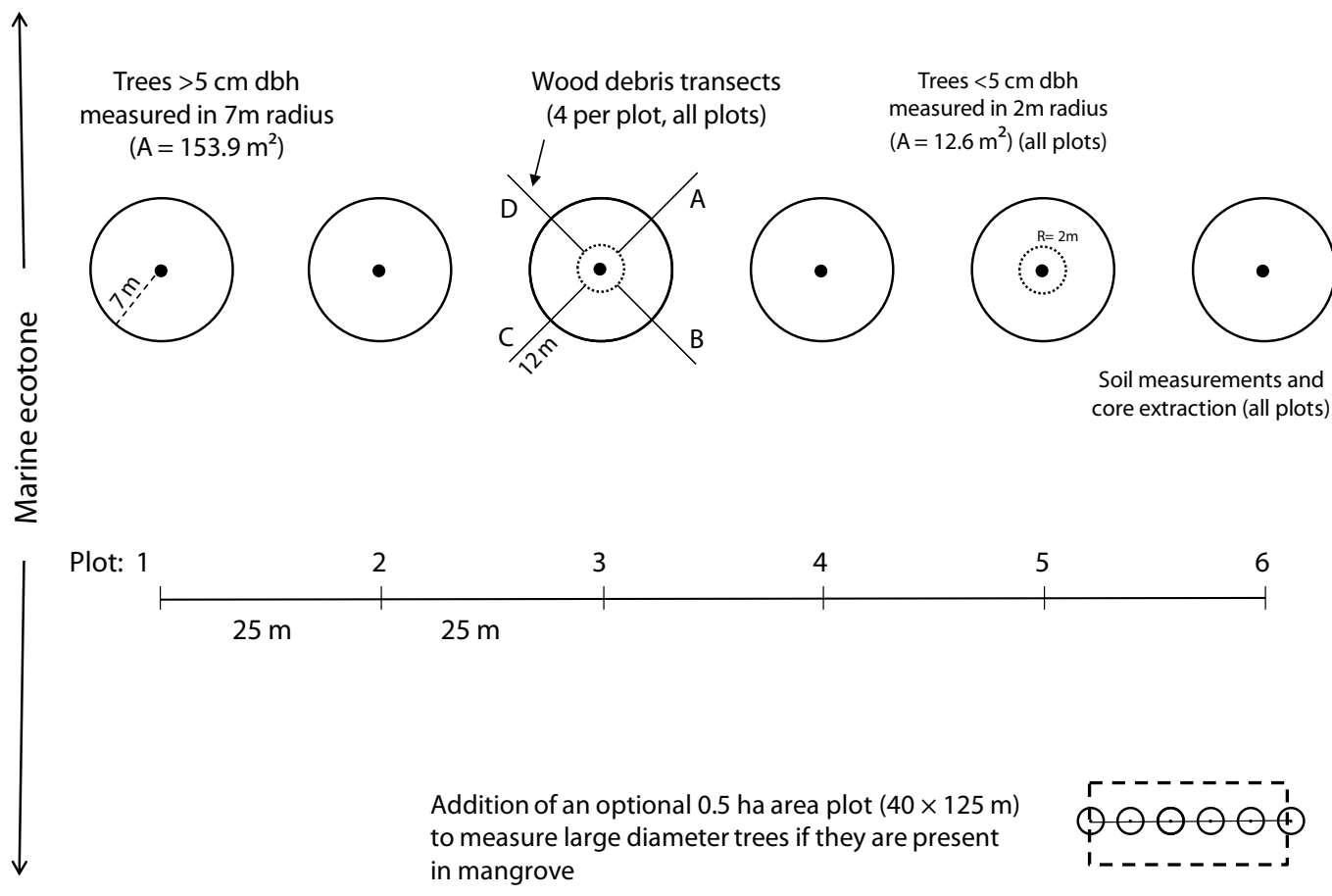

Figure 6. Schematic of plot layout for mangroves sampled in the Indo-Pacific Forest Carbon study and the Tropical Wetlands Initiative for Climate Change Adaptation and Mitigation

$\mathrm{dbh}=$ diameter at breast height.

to the marine-mangrove ecotone, with the first plot established $15 \mathrm{~m}$ inland from this ecotone. In addition to providing a good estimate of composition, structure and ecosystem carbon pools, this design also allows examination of relationships along tidal and elevation gradients. This design is advantageous because the linear plot arrangement captures much of the inherent variation in mangroves along the gradient from marine edge to uplands. The circular plots are relatively easy to establish and efficient to measure. The nested plots are designed such that the largest trees (live and dead) are measured in the $7 \mathrm{~m}$ radius circular plots, and small trees and seedlings in the smaller $2 \mathrm{~m}$ circular subplots. Wood debris is measured in four planar intersect transects per subplot. Soil samples of depth, bulk density and carbon concentration are collected at prescribed depths near the centre of each subplot. If an abundance of very large trees is present (e.g. $>50 \mathrm{~cm}$ diameter at breast height $[\mathrm{dbh}])$ this size class can be further measured in a $40 \times 125 \mathrm{~m}(0.5$ ha) rectangular plot surrounding the sampler circular plots (see inset in Figure 6).
Plot shape and size. Many plot sizes and shapes can adequately describe forest composition, biomass and ecosystem carbon pools. No single plot size and shape is optimal. For this reason we recommend using a nested plot design such as in Figure 6 where large trees are measured within the largest plot and smaller trees (i.e. those $<5 \mathrm{~cm} \mathrm{dbh}$ ) are only measured in the smaller nested plot. The plot designs presented in figures 6-9 could be modified to more optimally measure the mangrove in any particular study. Reliable data can be obtained from circular or rectangular plots. The shape and size of sample plots is a trade-off between accuracy, precision, time and cost. The objective in plot design is to achieve optimal shape, size, and sampling intensity to accurately describe the ecosystem properties without needless redundancy. As such, plot size, layout and intensity should be designed with accuracy, sampling efficiency and safety in mind. Most forest inventories and carbon assessments are designed with a series of nested plots, with sizes corresponding to the spatial scale of the forest component of interest (figures 6, 7, 8 and 9). For example, the largest trees and rare plants are sampled in the largest plots. The high 

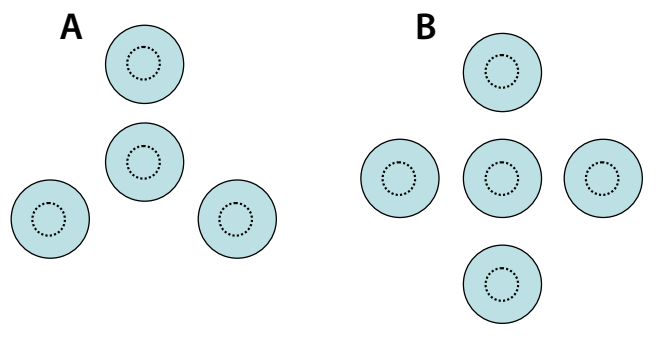

C

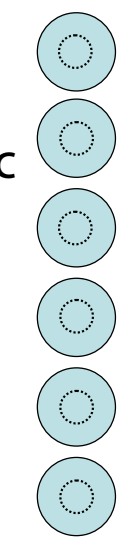

\section{Figure 7. Examples of clustered plot designs used in different forest inventories.}

Notes: The 'plot' is composed of a series of 'subplots'. A and B are from the United States' Forest Inventory and Analysis (FIA), Forest Health Monitoring (FHM), and Current Vegetation Survey (CVS) programmes (e.g. USDA 2008) - used for efficiently assessing larger ground areas and increasing overall precision. $\mathrm{C}$ is from the Indo-Pacific Forest Carbon Study (Kauffman and Cole 2010, Murdiyarso et al. 2010, Donato et al. 2011) used for assessing directional gradients, reducing species contagion, and increasing precision.

density of smaller trees, lianas and palms make it practical to sample them in a smaller plot or series of plots. Litter, seedlings and herbs can be adequately sampled in even smaller plots.

Clustering. Another consideration is whether, at a given plot, multiple sample units are clustered together, or if a single sample unit is employed. Many well-established forest inventory programmes, such as the United States' Forest Inventory and Analysis (FIA) programme, use clustered sample units, commonly referred to as 'subplots' (Figure 7). Because they are spread across a larger proportion of the sampled site than a single plot of the same area, clustered plot design captures more microsite variation in vegetation, soils, etc., thereby reducing among-plot variation and increasing overall precision.

In mangroves, movement by those performing the survey is made difficult by the presence of pneumatophores, mud, deep channels, standing water and extremely dense thickets composed of stilt roots and main stems. It is important to consider these ecosystem attributes in sample design and layout. The difficulties in movement encountered by field technicians, the desire to minimise trampling damage resulting from measurements and movement, and the need to encompass the variation along the inherent gradients of mangroves, led Kauffman and Cole (2010) and Donato et al. (2011) to use a linear plot layout (figures 6, 7C and 9) in their studies of mangrove carbon pools. Linear designs are more efficient to establish, and result in less trampling damage than clustered plots such as those in figures $7 \mathrm{~A}$ and $7 \mathrm{~B}$.

Figure 9 illustrates a plot layout for measuring dwarf mangroves (mangle chaparro). These low-statured uniform stands may be quite dense $(>40,000$ individuals/ha) thus requiring smaller plots. Aboveground biomass in these plots is measured in 6 half-circle $6.3 \mathrm{~m}^{2}$ subplots. Because of the uniformity in stands, transect length between subplots can be shorter in distance. The shorter transect length is also more efficient as these stands can be quite difficult to walk and work in. Soils and downed wood (if present) are measured using the same methods as in other mangrove forests (Figure 6).

Number of plots or stands to be sampled. It is important that sampling is carried out with statistical rigor. The number of plots should be determined by the desired precision level. This determination is best made based on local knowledge and experience, as well as simple statistical tests. An online tool for calculating the number of plots is available at: http:// www.winrock.org/Ecosystems/tools.asp (Winrock International 2011).

Typically the desired precision level is to target within $10 \%$ of the true value of the mean at $95 \%$ confidence level. To estimate the number of plots required, some prior knowledge of the variation in carbon pools within the project area is needed (e.g. from a previous inventory if available, or from a preliminary sample of 6-10 plots).

At the simplest level, the number of plots required should be calculated as follows:

Minimum number of sample plots $(n)=\left(\frac{\mathrm{t}^{*} \mathrm{~s}}{\mathrm{E}}\right)^{2}$

$n=$ the number of sample plots, $\mathrm{t}=$ the sample statistic from the $t$-distribution for the $95 \%$ confidence interval, $t$ is usually set at 2, as sample size is unknown at this stage; $s=$ standard deviation expected or known from previous or initial data; $\mathrm{E}$ $=$ allowable error or the desired half-width of the confidence interval, calculated by multiplying the mean carbon stock by the desired precision, i.e. mean * 0.1 (for $10 \%$ precision). 


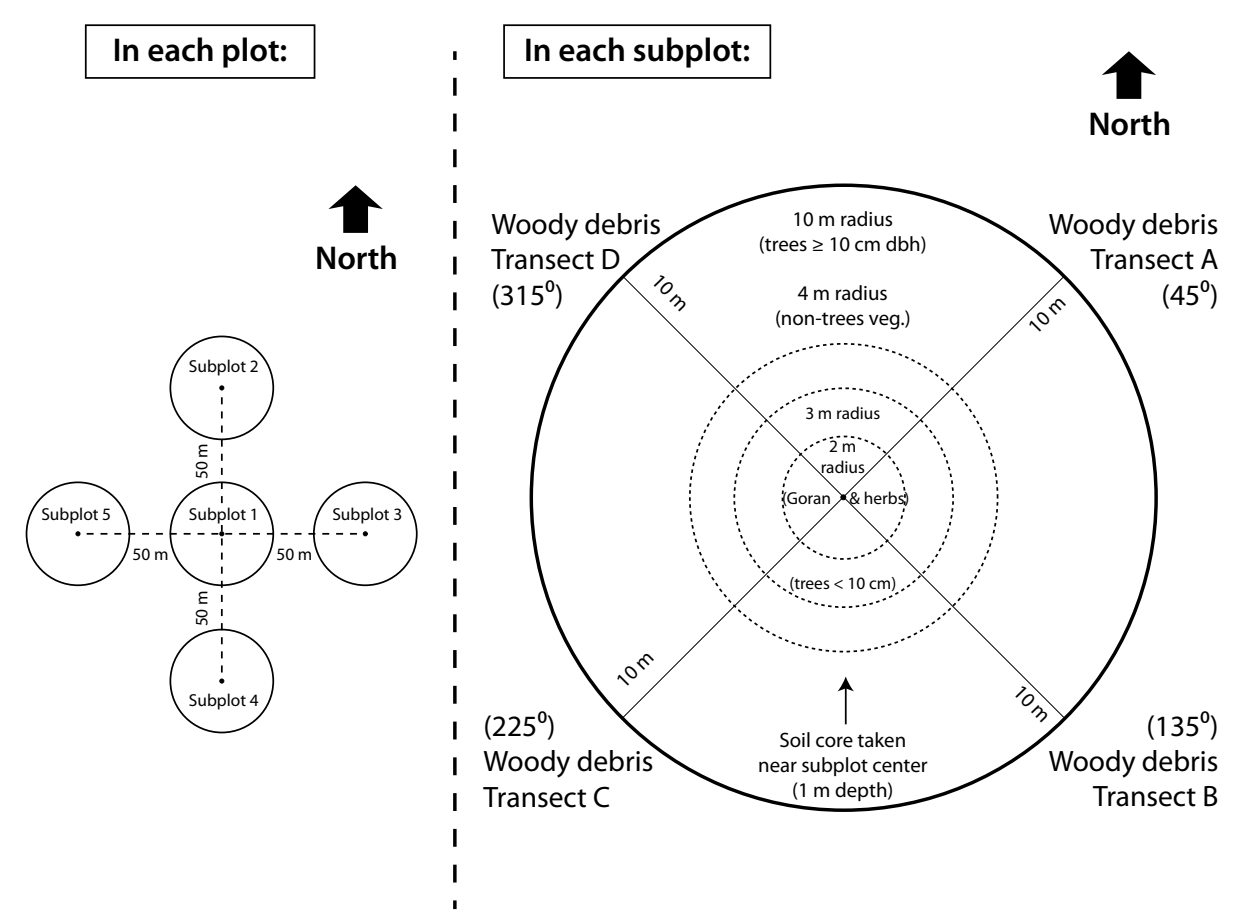

Figure 8. The plot layout for carbon stock sampling of mangroves within the Sundarbans Reserve Forest, Bangladesh

Note: A plot such as this can be either permanent or temporary. To ensure relocation in the future, all subplot centres should be determined via high-precision GPS and marked with permanent stakes; in the case of this layout, at the subplot centres.

Source: Donato et al. (2009)

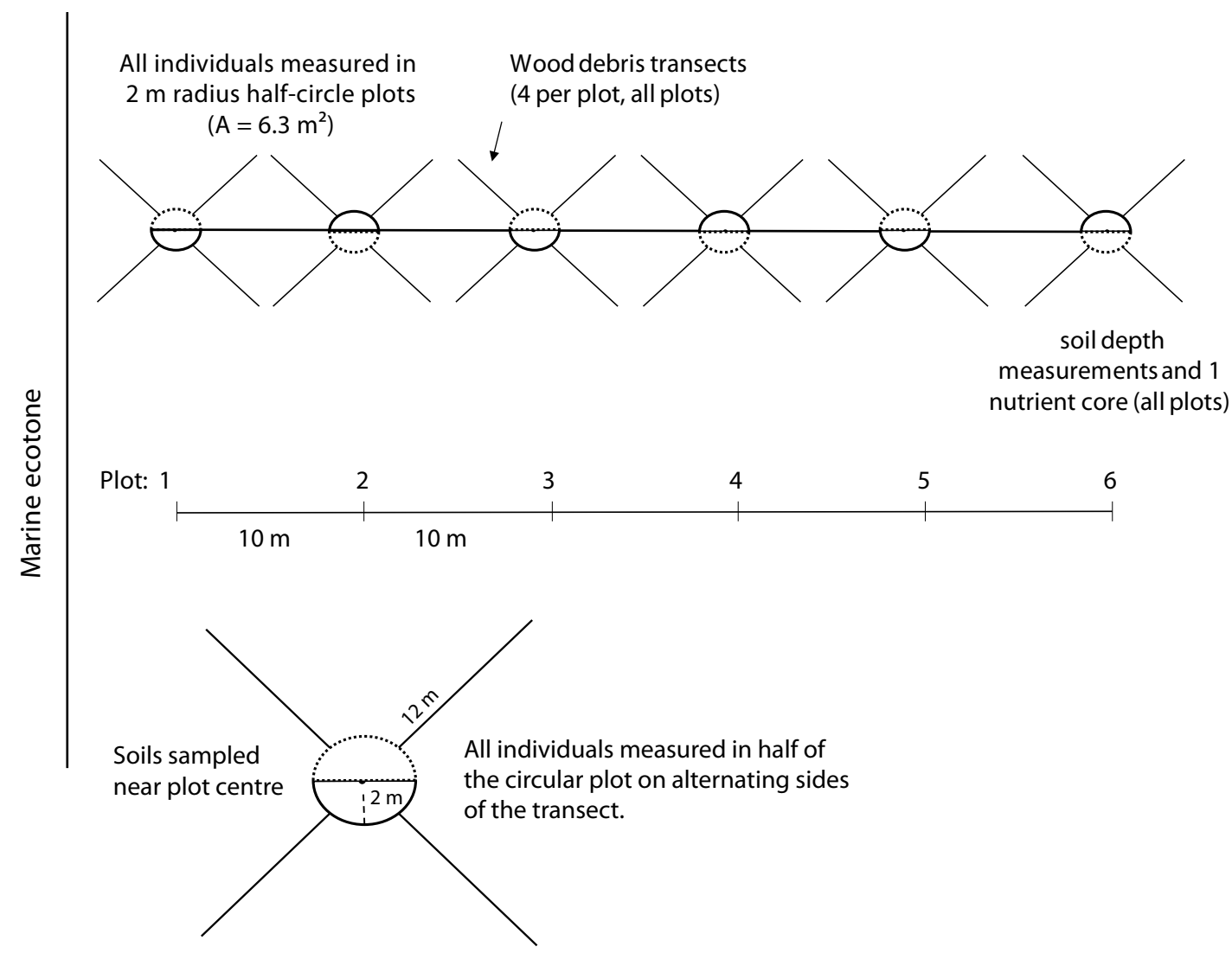

Figure 9. A recommend plot layout to measure carbon stocks, composition and structure of dwarf mangrove communities (mangle chaparro) 
If the project area is stratified into different mangrove forest types, the sample size determination must be conducted for each forest type. Finally, the minimum sample size should be increased by about $10 \%$ to allow for plots that cannot be relocated or are lost due to unforeseen circumstances.

Location. It is important to avoid bias in locating plots. Plot locations should be selected with no prior knowledge of composition and structure (at the site level). This is best accomplished by determining plot locations prior to going to the field. Plot locations can be arranged randomly or systematically (e.g. Figure 10). Both approaches are acceptable and tend to yield similar precision. However, if some parts of the project area or strata have higher carbon content than others, systematic selection usually results in greater precision than random selection. Systematic sampling is also widely recognised as credible (Pearson et al. 2007).

\section{Step 5: Determine measurement frequency}

How often to measure, or the monitoring interval, depends on the issues of interest, as well as the rate of expected change in the mangroves being sampled. Causes of change in mangroves are numerous and variable in their impact. These causes of carbon stock change include natural disturbances such as typhoons or hurricanes, natural rates of carbon sequestration, changes in land cover due to land-use activities (e.g. aquaculture establishment), and alterations due to climate change (e.g. sea level rise). Frequency of sampling may also be determined by established requirements for participation in carbon markets.

Frequency of monitoring also involves consideration of the costs and benefits of sampling. Frequent sampling (i.e. annually) may yield the best estimates but is costly and likely more than is needed to monitor changes. Given the dynamics of forest processes, forests are generally measured at intervals of about 5 years (Pearson et al. 2005, 2007). For carbon pools that respond more slowly, such as mineral soils, even longer periods can be used perhaps 10 or 20 years between sampling events. A

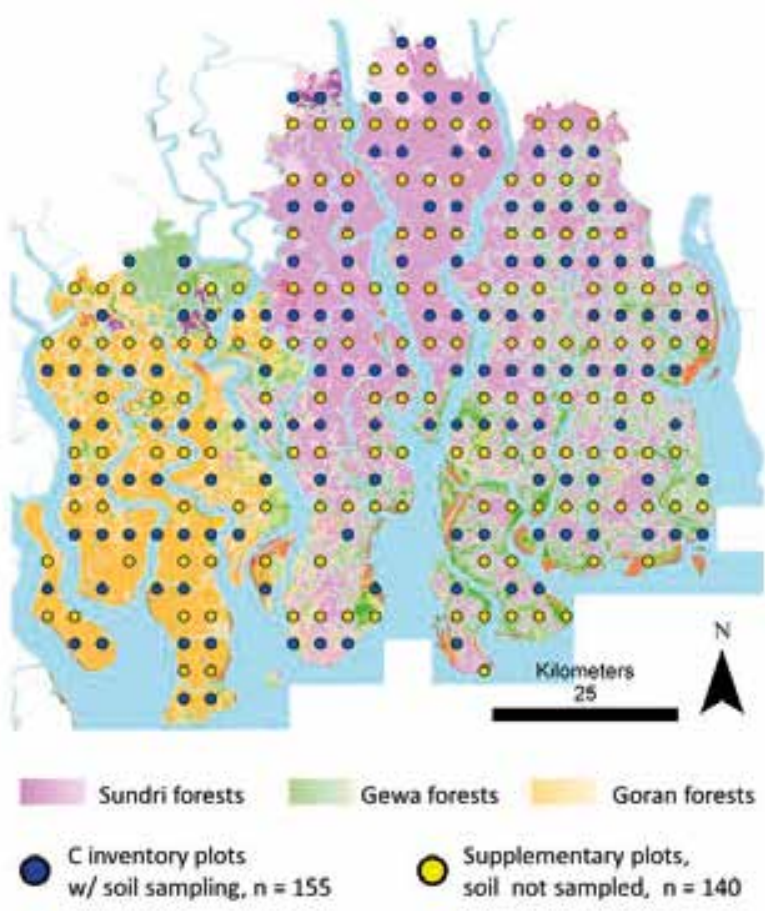

Figure 10. An example of a systematic sampling grid from the Sundarbans, Bangladesh.

Note: This sampling scheme was employed for a carbon and forest inventory of the Sundarbans Reserve Forest, Bangladesh. A systematic grid was employed with 295 plots spaced at regular intervals of latitude and longitude. Gaps in the grid are due to watercourses. Colours correspond to different vegetation types.

Source: Donato et al. (2009)

disadvantage of long intervals is the risk of natural or anthropogenic disturbance, the effects of which may by missed with widely spaced monitoring intervals (Pearson et al. 2007). This would particularly be true of mangroves with organic soils where landcover change may result in rapid changes in soil carbon pools. Also, unexpected events such as strong tropical storms (or a dramatic human-caused land-cover change) may justify sampling at more frequent intervals, to capture events that may have dramatic effects on mangrove carbon dynamics. Finally, measurement within 5-year intervals may be necessary to claim carbon market credits (Pearson $e t$ al. 2005). 


\section{Field procedures}

\subsection{Unique considerations for measuring carbon in mangroves}

Mangroves have many unique features that must be considered in project design. They often have extremely high stem densities with abundant prop roots and/or pneumatophores (figures 1 and 2). Mangroves are frequently dissected by tidal channels that are difficult to cross, especially at high tides. These and a number of other hazards limit mobility and create safety concerns.

Most mangroves are also subject to semidiurnal tidal cycles and can only be sampled during low tides, limiting both the timing and duration of the sampling, especially for components on the forest floor. In the lowest elevation mangroves, sampling may be limited to low tidal periods of as little as 3-4 hours (Figure 11). This narrow window necessitates an efficient sampling protocol.

The 'Rule of Twelfths' provides insight into the length of time available to sample (Figure 11). The water level during the tidal cycle changes in a predictably nonlinear pattern:
- During the first hour after high water, the water drops $1 / 12$ of the full range.

- During the second hour, it drops an additional 2/12.

- During the third hour, it drops an additional 3/12.

- During the fourth hour, it drops an additional 3/12.

- During the fifth hour, it drops an additional 2/12.

- During the sixth hour, it drops an additional $1 / 12$.

- This pattern repeats as the tide rises again.

\subsection{General information to be collected at each plot}

The following information should be recorded at each sample plot:

- plot identifier - name and/or number of the sampled plot or stand;

- general location of plot/sampled stand and other identifying information (e.g. management district, etc.);

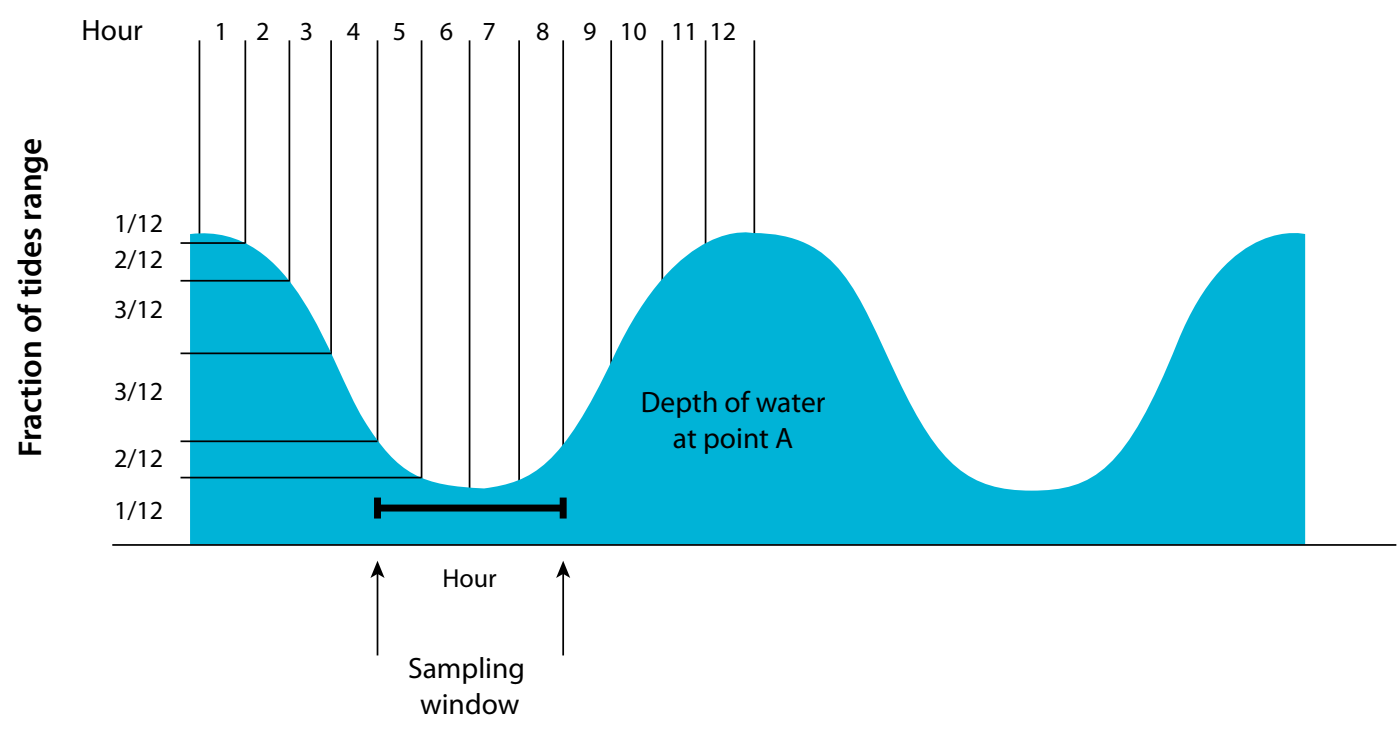

Figure 11. The cycle of tides and the 'Rule of Twelfths' that influence the optimal times to sample vegetation and soils in mangrove ecosystems.

Note: Hours 0 and 12 are the approximate high tides; hour 6 is the approximate low tide. A period of minimal change in water level occurs for about 2 hours on either side of low tide, creating a sampling window of about 4 hours, beginning at hour 4 and continuing through hour 8 . Sampling time periods in mangroves are sometimes longer at higher elevations. 
- date;

- crew members present;

- GPS coordinates and precision $( \pm \mathrm{X} \mathrm{m})$;

- directions to the plot location.

The following general plot information should be recorded as well:

- Site category: forest, dwarf or scrub (<5 m height), or other (if other, describe);

- Ecological condition and land use: intact, degraded or deforested;

- Topography (microrelief): flat, depression, levee or hummock, etc.;

- Geomorphic setting: river delta, coastal fringe, interior or basin, etc.;

- Soil description: organic or mineral soil - sand, clay, silts, etc.;

- Disturbance evidence:

o Cyclone damage: not evident, light, moderate or severe;

o Timber harvest: not evident, low $(<30 \%$ basal area), medium (30-70\%), or high ( $>70 \%)$. Also describe the harvest;

o Other disease or disturbance: not evident, light, moderate or severe. Also describe the other disease or disturbance.

In addition to descriptive data, it is valuable to establish permanent photo points in plots. Protocols are usually established to maintain consistency for all sampled plots. For example, in the inventory of the Sundarbans, Bangladesh (Figure 10), four digital photos were taken - one in each cardinal direction (north, south, east, west) - at plot centre (Donato et al. 2009). Photos should be stored electronically with other project data. It is important to back up photos, and all other data collected, at the conclusion of each day's activities.

At the end of every field outing, data sheets should be reviewed by the recorder for completeness, legibility and accuracy. Once satisfied with the quality of data recorded, the recorder (or other data reviewer) should write their name and the date of the review, along with any notes on issues that were noticed during the check, so they can be addressed in the future. Similarly, when data is entered into a computer, each data sheet should be compared to entered data to ensure accuracy. Once the person entering data has compared the computer entry to the data sheet and corrected any errors, they should write their name and the date of data entry at the bottom of the data sheet. Any issues should be noted so that they can be corrected in the future. In addition, a subsample of data sheets should be compared to the computer entry by someone other than the person who entered the data (minimum $10 \%$, the exact number is dependent on the quality control plan and the number of errors found - more errors warrant more data reviews). The data reviewer should also write their name and the date of the data review, along with any notes on issues that were apparent or corrections that were made. It is important that all issues noted on the data sheets are brought to the attention of the field supervisor so that preventative measures can be taken.

\subsection{Specific measurements in plots and subplots}

\subsubsection{Trees}

Trees dominate the aboveground carbon pool and are an obvious indicator of land-use change and ecological condition. It is essential to measure trees thoroughly and accurately. The basic concept is that measurements of stem diameter (and sometimes height) are used to estimate tree biomass and carbon stock using allometric equations by species (discussed thoroughly in 'Laboratory and data analysis').

Basic data measurements to be recorded for all mangrove forest surveys include species identification, main stem diameter, and whether the individual tree is alive or dead. Main stem tree diameters are typically measured at $1.37 \mathrm{~m}$ above the ground, which is also called the diameter at breast height (dbh). As in all forests, this is not always a straightforward process due to anomalies in stem structure. For trees with tall buttresses exceeding $1.37 \mathrm{~m}$ above ground level, stem diameter is usually measured at the point directly above the buttress. For stilt rooted species (e.g. Rhizophora spp.), stem diameter is often measured above the highest stilt root (Clough and Scott 1989, Komiyama et al. 2005). For some individuals with prop roots extending well into the canopy, it is not necessary, practical or accurate to measure above the highest prop root. Typically, tree diameter is measured above the stilt roots, where a true main stem exists. In permanent plots, it is quite important to mark the point of measurement (POM) when it is not at 1.37 $\mathrm{m}$ above ground level (dbh). This is accomplished by placing the tree tags exactly at the POM, and/or 

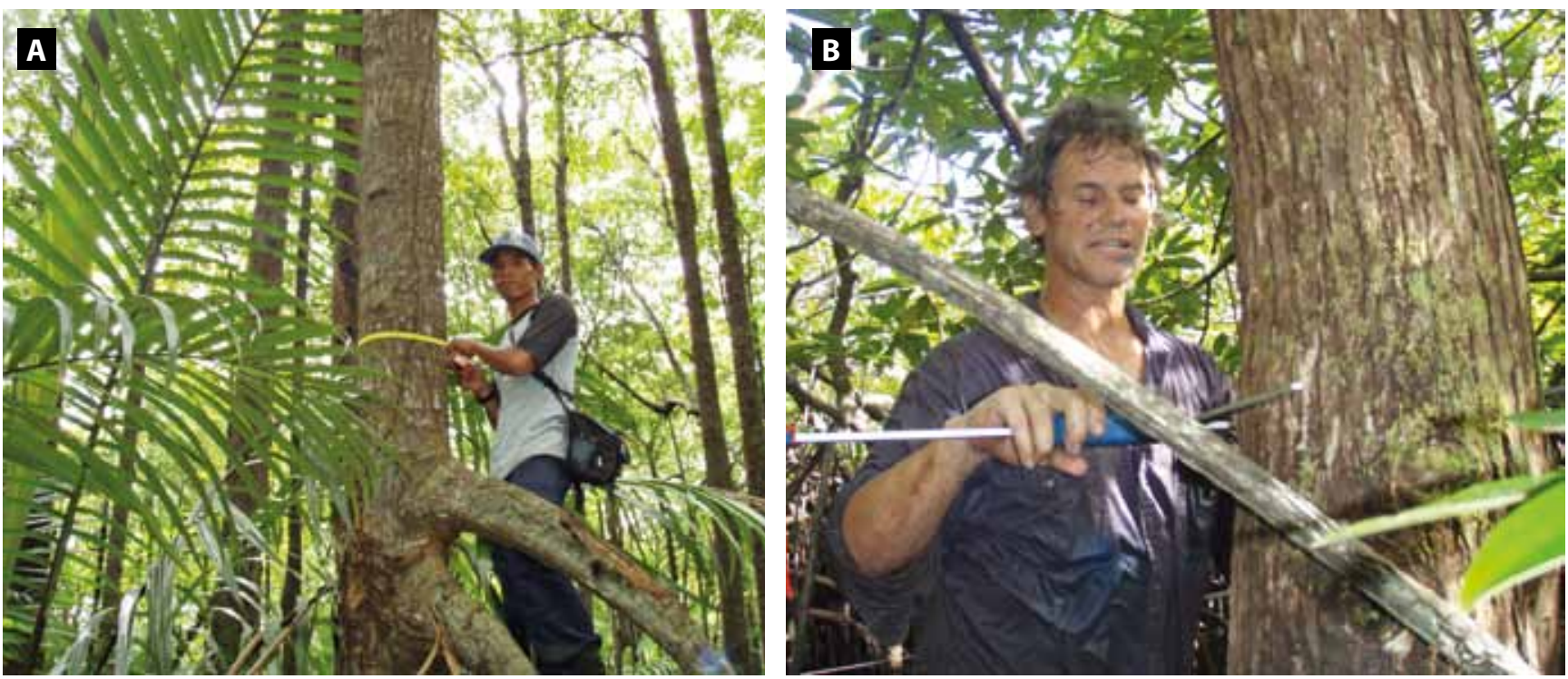

Figure 12. Measuring tree diameter at breast height (Left photo by Dan Donato/University of Wisconsin; right photo by Chris Heider/Watersheds Professional Network)

Notes: A) Measurement of a large Rhizophora apiculata with a diameter tape, Tanjung Puting National Park, Indonesia; this demonstrates measuring above the highest stilt root. B) Measurement of a Sonneratia alba (in the Republic of Palau) using a tree caliper. Tree calipers are useful for rapid surveys or assessments but are not recommended for permanent or repeated samples.

by painting a ring at the POM. A tree is included in the survey if at least $50 \%$ of the main stem is rooted inside the plot or subplot perimeter. Diameters are usually measured with a diameter tape or, if a onetime rapid assessment, a tree caliper (Figure 12).

In many nonpermanent surveys of upland forests, only trees $>10 \mathrm{~cm}$ dbh are measured (GOFC-

GOLD 2011). This is because smaller trees often constitute a relatively insignificant proportion of the total ecosystem carbon stock (Hughes et al. 2000, Cummings et al. 2002). For many mangroves, however, smaller trees can dominate the stand composition (Kauffman and Cole 2010; Figure 1A). For permanent plots where trends in carbon gain or loss are being monitored, it is important to measure all trees. As previously stated, smaller diameter trees may be measured in smaller nested subplots to maximise sampling efficiency without compromising accuracy (figures 6-9).

In forested mangroves, seedlings are defined as individual trees $<1.37 \mathrm{~m}$ in height. Usually they are counted and measured in the smallest plots. Live seedlings can be recorded as a simple count of individuals; an average dry mass per seedling can be utilized to determine their plot-level biomass. This requires destructive sampling of a random subset of seedlings, in which they are collected (from outside any sample plots) and oven dried to obtain dry mass. Seedling mass is then calculated as the product of seedling density multiplied by average seedling mass.

Trees that are dead and standing should be recorded as such. Other measurements of dead standing trees are the same as for live trees. The decay status of dead trees should be recorded as follows (Figure 13):

- Status 1: Small branches and twigs are retained; resembles a live tree except for absence of leaves. Typically the allometric equation for a live tree and then subtracting for leaf biomass is the most accurate to determine biomass of Status 1 dead trees.

- Status 2: No twigs or small branches; may have lost a portion of large branches.

- Status 3: Few or no branches, standing stem only; may be broken-topped. These require a different approach to biomass estimation:

o For Status 3 dead trees, also record diameter at base of tree, and total tree height using a laser tool or clinometer.

o Only base diameter and height are measured for stumps (Status 3 dead trees not reaching dbh because they were cut or naturally broken off). Volume and biomass are estimated using formulas for calculation of a cylinder. 


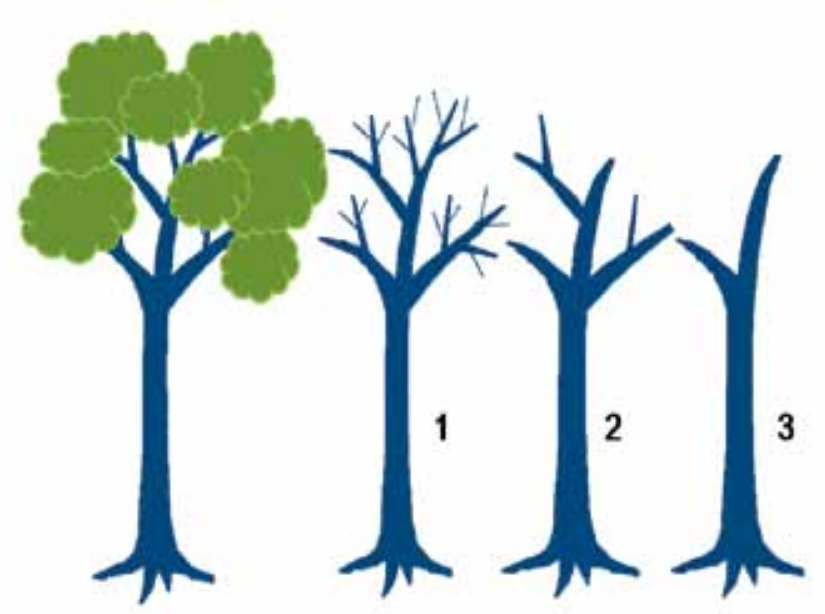

Figure 13. The dead tree decay status classes for tropical trees.

Note: 1) Status 1 trees are recently dead and maintain many smaller branches and twigs. 2) Status 2 trees have lost small branches and twigs, and a portion of large branches. 3) Decay status 3 applies to standing 'snags', where most branches have been lost and only the main stem remains. The main stem is often broken.

Source: Modified from Solichin (2009)

Large lianas rarely exist in mangroves but if present they can be measured just as trees. Protocols and approaches for the measurement of lianas have been thoroughly described by Gerwing et al. (2006) and Schnitzer et al. (2006). Palms with woody trunks can be measured in the same manner as broad-leaved trees. Parameters of the palm to be measured (dbh, height, etc.) depend on the allometric equation used to determine palm mass. The most frequently used variables to determine palm mass is $\mathrm{dbh}$ and the height of the main stem (to base of leaves).

\subsubsection{Shrub and dwarf mangroves}

A great percentage of the world's mangroves have an aboveground structure of small trees less than a few meters in height, often referred to as dwarf mangrove, scrub, or mangle chaparro. There is a need for allometric equations to determine aboveground biomass for these kinds of mangroves. The best predictors of mass for these smaller individuals are stem diameter at $30 \mathrm{~cm}$ aboveground level, crown area, height and/or crown volume (Figure 14). The equations to estimate biomass of dwarf mangroves have been developed in south Florida, USA (Ross et al. 2001, Coronado-Molina et al. 2004) and Puerto Rico (Cintron and Schaeffer-Novelli 1984). The equations in Ross et al. (2001) utilise the main stem diameter at $30 \mathrm{~cm}$ above the ground surface and crown volume to predict aboveground biomass of individual mangroves; those of Cintron and Schaeffer-Novelli (1984) used height and diameter.
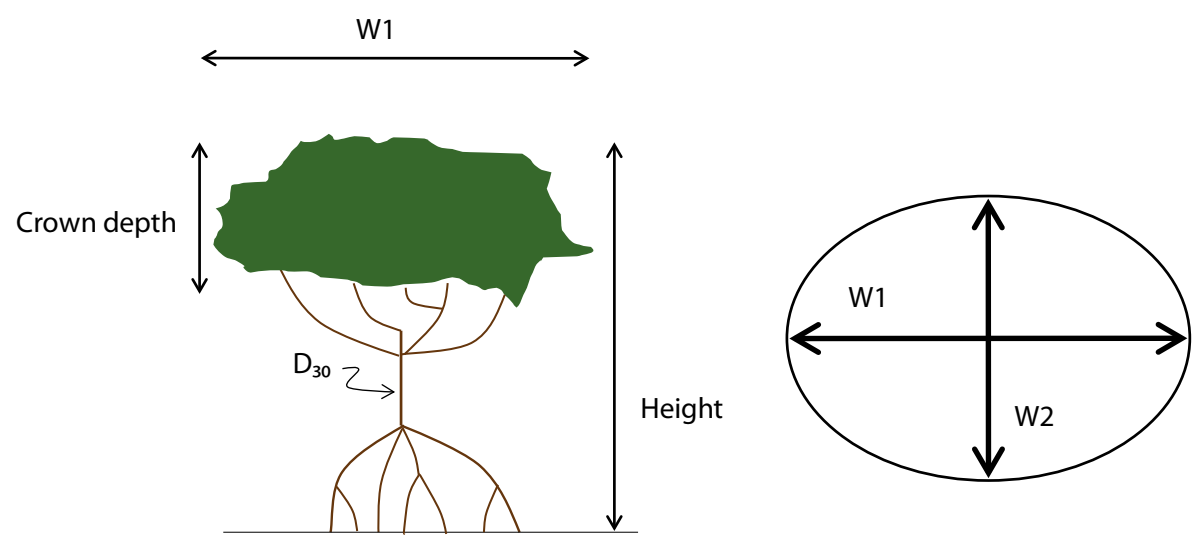

Elliptical crown area $=(\mathrm{W} 1 \times \mathrm{W} 2 / 2)^{2 *} \pi$;

Where $\mathrm{W} 1$ is the widest length of the plant canopy through its centre and W2 is the canopy width perpendicular to W1. Crown volume = elliptical crown area * crown depth. Height is measured from the sediment surface to the highest point of the canopy. $D_{30}$ is the mainstem diameter at $30 \mathrm{~cm}$.

Figure 14. The field measurement techniques for determining biomass of dwarf mangroves.

Note: Aboveground biomass of these small trees is best predicted through allometric equations, where aboveground biomass is the dependent variable, and diameter, height, crown area and/or crown volume are independent variables 
It would be useful to develop such equations for other areas. To develop an allometric equation, at least 15-25 trees of each species in question, encompassing samples ranging in size from the smallest seedlings to the largest individuals, would be destructively harvested. In the laboratory, individual trees are dried and weighed to obtain biomass. Allometric equations can then be developed where crown diameter, crown volume, crown area and/or main stem diameters are independent variables used to predict aboveground biomass (the dependent variable).

Relatively small plots are used to measure the biomass of dwarf mangroves because they are typically very dense (Figure 1). Examples of plot sizes and shapes include $2-\mathrm{m}$ radius, half-circle plots $\left(6.3 \mathrm{~m}^{2}\right.$; Figure 9). For each dwarf mangrove in each plot, the tree characteristics listed in Figure 14 are measured (i.e. height, W1 and W2 in $\mathrm{cm}$, and $\mathrm{D}_{30}$ in $\mathrm{mm}$ ). A tape measure is the best tool to measure height and crown widths and a digital caliper is best to measure stem diameter.

\subsubsection{Canopy}

Canopy cover is another descriptor of forest structure. Changes through time may be related to tropical storm effects, land use, or long-term effects of climate change. In addition, canopy coverage measurements may aid in interpreting remotely sensed data to monitor forest condition.

Several field and remote methods to measure canopy coverage are discussed in other forest measurement publications. These include fish eye lenses on cameras, remotely sensed data, and a spherical densiometer.

The densiometer is a gridded convex mirror (Figure 15) that provides a simple and inexpensive approach to measuring canopy cover. The densiometer is held $30-40 \mathrm{~cm}$ in front of your body and at elbow height, so that your head is not visible in the mirror. Level the instrument using the level bubble. In each square of the grid, imagine four dots, representing the centre of quarter-square subdivisions of each of the squares (Figure 15). Systematically count the number of dots not occupied by canopy (dots in which you can see sky). Record this number on the datasheet.

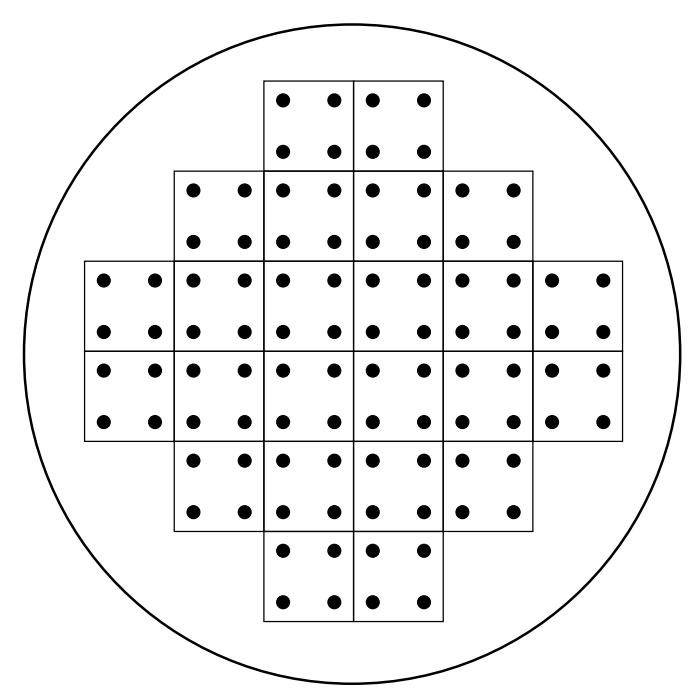

Figure 15. Schematic of densiometer mirror, with the four dots depicted in each square

A number of locations should be sampled in each plot. For example, the centre of each subplot could be measured in the layouts depicted in figures 6, 7, 8 , and 9. Make four readings at each sampling point - facing north, south, east, and west. The canopy cover is estimated by taking the average of these four readings.

\subsubsection{Non-tree vegetation}

Most mangroves do not contain a significant amount of non-tree or understory vegetation (Snedaker and Lahmann 1988). The most notable exception is the nipa palm (Nypa fruticans) of the Asia-Pacific region. Approaches to sampling these vegetation components will depend on their density, structure and distribution. A number of excellent publications address approaches to sampling non-tree vegetation (e.g. Mueller-Dombois and Ellenberg 2003).

\subsubsection{Palms}

Biomass of non-woody palms (e.g. Nypa fruticans), small lianas and herbaceous vegetation may be determined either through non-destructive sampling or destructive harvests (which is most common for herbaceous vegetation such as ferns, sea grasses, grasses, sedges, rushes, and broad-leaved herbs). Nondestructive approaches are necessary for plots that will be revisited over time, especially for perennial species. Nypa can be non-destructively estimated 
through determination of average individual leaf mass and thereafter simply counting all palm leaves that occur within the sample plot. Given that nipa palm leaves may exceed $5 \mathrm{~m}$ in length, nondestructive methods are the most practical.

To determine average leaf mass, at least 15-25 palm fronds from different individuals should be collected from outside any sample plots. The samples should cover the size distribution of the individual leaves. Each sampled frond is cut at ground level and transported to the laboratory to determine dry weights. This allows for the estimation of the average dry weight mass for individual nipa leaves. In actual plot surveys, only the number of nipa leaves within a plot is counted. The mass of nipa palm is then calculated as the number of leaves (or leaf density) in the plot multiplied by average leaf mass.

\subsubsection{Forest floor - litter}

The litter layer is defined as the recently fallen nonwoody, dead, organic material on the soil surface. Typically, it consists of dead leaves, flowers, fruits, seeds and bark fragments. In most mangroves, the amount (and therefore carbon stock) of this material is usually negligible due to the high efficiency of detritus-consuming crabs, as well as export through tides and seasonal river flooding.

Litter in most biomass studies is destructively sampled through collection from microplots. Microplot sizes usually range from $30 \times 30 \mathrm{~cm}$ to 1 $\mathrm{m}^{2}$. A common plot size is $50 \times 50 \mathrm{~cm}$. All organic surface material, excluding woody particles, is collected into a sturdy bag or container. The bags are labelled with the location, date, plot and sample number. Given the wet nature of mangroves, prelabelled plastic bags may be most efficient for litter samples. At the end of the sample day, the samples should be transported out of the field, placed in a drying oven, and dried to constant mass. Due to the constraints of carrying bulky samples from the field and the limited availability of oven drying space, especially in rural field settings, the wet weight of the sample can be determined and then a well-mixed representative subsample extracted and dried to a constant weight. The ratio between the wet and dry mass of the subsample is determined (Cummings et al. 2002). Whole litter samples are then adjusted to a dry weight basis.

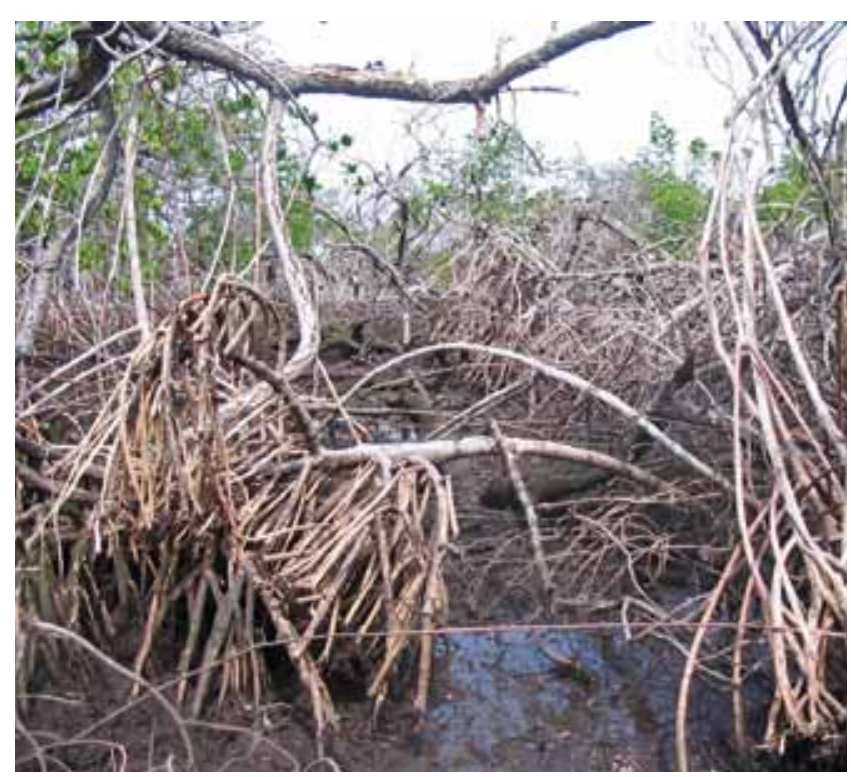

Figure 16. The accumulation of dead and downed wood in a mangrove ecosystem following a severe typhoon (Photo by J.B. Kauffman/Oregon State University)

Note: Large quantities of downed wood are often present following disturbances such as severe tropical cyclones. In this example, large numbers of Rhizophora and Sonneratia were killed and/or were uprooted following Typhoon Sudal, Yap, FSM.

\subsubsection{Pneumatophores}

Pneumatophores of species of the genera Avicennia, Bruguiera and Sonneratia can be of significant structure and biomass (Figure 2). Unlike the prop roots on Rhizophora, these tree parts are not included in the allometric equations of biomass for trees. Pneumatophore density can be determined by counting their numbers in the microplots established for the litter layer. A mean mass per pneumatophore can then be used to calculate mass of pneumatophores in the sampled stand. Again, this would require destructive sampling of pneumatophores to obtain an average mass. Similarly, an allometric equation using pneumatophore height to predict biomass could be developed, and would be of value in permanent plots. If such an equation were developed, each pneumatophore in a microplot would need to be measured for height. This would be most relevant for those species containing large pneumatophores, such as Sonneratia alba (Figure 2). A mean mass per pneumatophore would be most efficient for small, dense pneumatophore-producing species, such as Avicennia species. 


\subsubsection{Dead and downed wood}

Several guides describe methods for determination of downed wood volume and mass (Brown 1971, Harmon and Sexton 1996, Waddell 2002). Dead and downed wood can be a significant component of aboveground biomass, particularly following natural disturbances such as tropical cyclones (Figure 16). It performs a number of important ecological functions in mangrove ecosystems. Landuse and/or land-cover change may also increase the quantity of downed wood on the mangrove forest floor. To accurately assess ecosystem carbon pools and influences of natural and human disturbances, dead and downed wood are important variables to measure. Downed wood is usually sampled either by plot-based sampling or by the line-intersect method (Brown and Roussopoulos 1974, Waddell 2002, Baker and Chao 2009). The most commonly used approach, and the one suggested here, is the nondestructive line intersect technique (van Wagner 1968). The line (or planar) intersect technique involves counting intersections of woody pieces along a vertical sampling plane (transect). In each plot, a series of transects should be established to measure this component (figures 6-9).

Any downed, dead, woody material (fallen or detached trunks, branches, prop roots or stems of trees and shrubs) that has fallen and lies within 2 $\mathrm{m}$ of the ground surface is measured using the nondestructive line intersect technique. Wood pieces of different size classes are measured along the transect
Table 2. Commonly used size classes of wood, based on the timelag constant

\begin{tabular}{lll}
\hline Description & Timelag & Diameter \\
\hline Fine & 1 hour & $0-0.6 \mathrm{~cm}$ \\
Small & 10 hour & $0.6-2.5 \mathrm{~cm}$ \\
Medium & 100 hour & $2.5-7.6 \mathrm{~cm}$ \\
Large & 1000 hour & $>7.6 \mathrm{~cm}$ \\
\hline
\end{tabular}

Source: Brown (1971) and Brown and Roussopoulos (1974)

(Figure 17). Wood debris can be categorised into four size classes based upon the timelag constant (Brown 1971): 1 hour, 10 hour, 100 hour and 1000 hour size classes; or alternatively, fine, small, medium, and large wood particles (Table 2). The size classes delineated in Figure 17 and Table 2 are regularly used in forest inventories, and convenient measurement tools exist to streamline field sampling based on these limits (Figure 18). An aluminium downedwood gauge, tape measure, or caliper can be used to determine the size class of each piece encountered (Figure 18).

Smaller pieces can be very abundant, so to save time, they are only sampled along subsections of each transect. Fine pieces ( 1 hour timelag) are only tallied for $1-2 \mathrm{~m}$ of transect. Small pieces (10 hour timelag) are only tallied for 2-3 m of transect. Medium pieces (100 hour timelag) are usually tallied for 3-10 $\mathrm{m}$ along the transect. In contrast to the smaller wood pieces, the diameter of each large wood piece

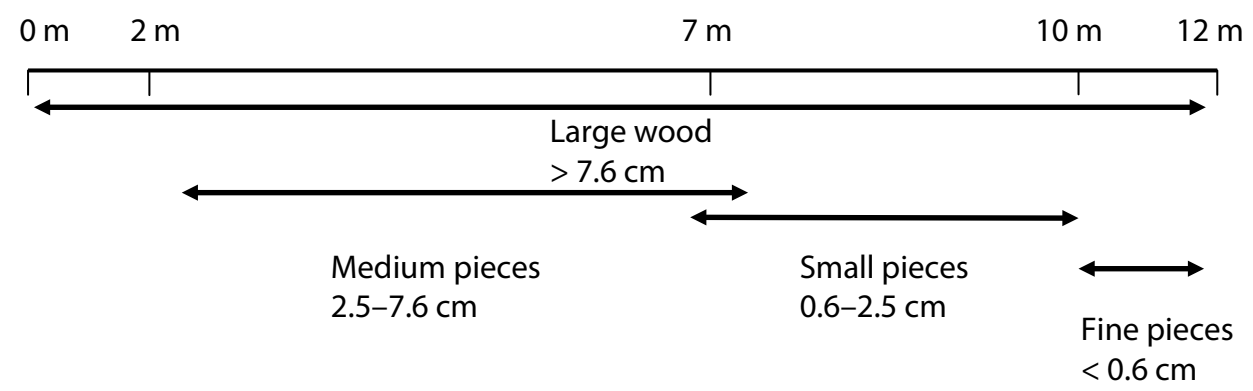

Figure 17. Example of a wood debris transect for sampling downed wood in mangroves using the line intersect technique (also referred to as the planar intercept technique)

Note: The diameter of each large wood piece encountered along the entire transect is measured. Smaller diameter pieces are counted along the designated lengths of the transect. In a practical sense, only the large wood fractions ( $>2.5 \mathrm{~cm}$ ) are a significant carbon pool. If desired, smaller pieces of wood can be ignored in the planar intersect and alternatively combined and sampled with the litter fraction. 
(1000 hour timelag) encountered along the entire transect is recorded (Figure 17).

Fine, small and medium pieces are tallied as the number of pieces that cross the transect tape. They are tallied separately for each size class. No diameter measurement is needed. Large pieces require more data to be collected. For each piece crossing the transect, its diameter is recorded at the point where the transect line crosses the midpoint of the wood particle (Figure 18). The decay status is also recorded: sound (machete bounces off or only sinks in slightly when struck) or rotten (machete sinks in deeply and wood is crumbly with significant loss). Usually, multiple wood debris transects are established and measured in plots. For example, following the design shown in figures 6 and 9, 4 wood debris transects were established in each of 6 subplots for a total of 24 transects per plot.

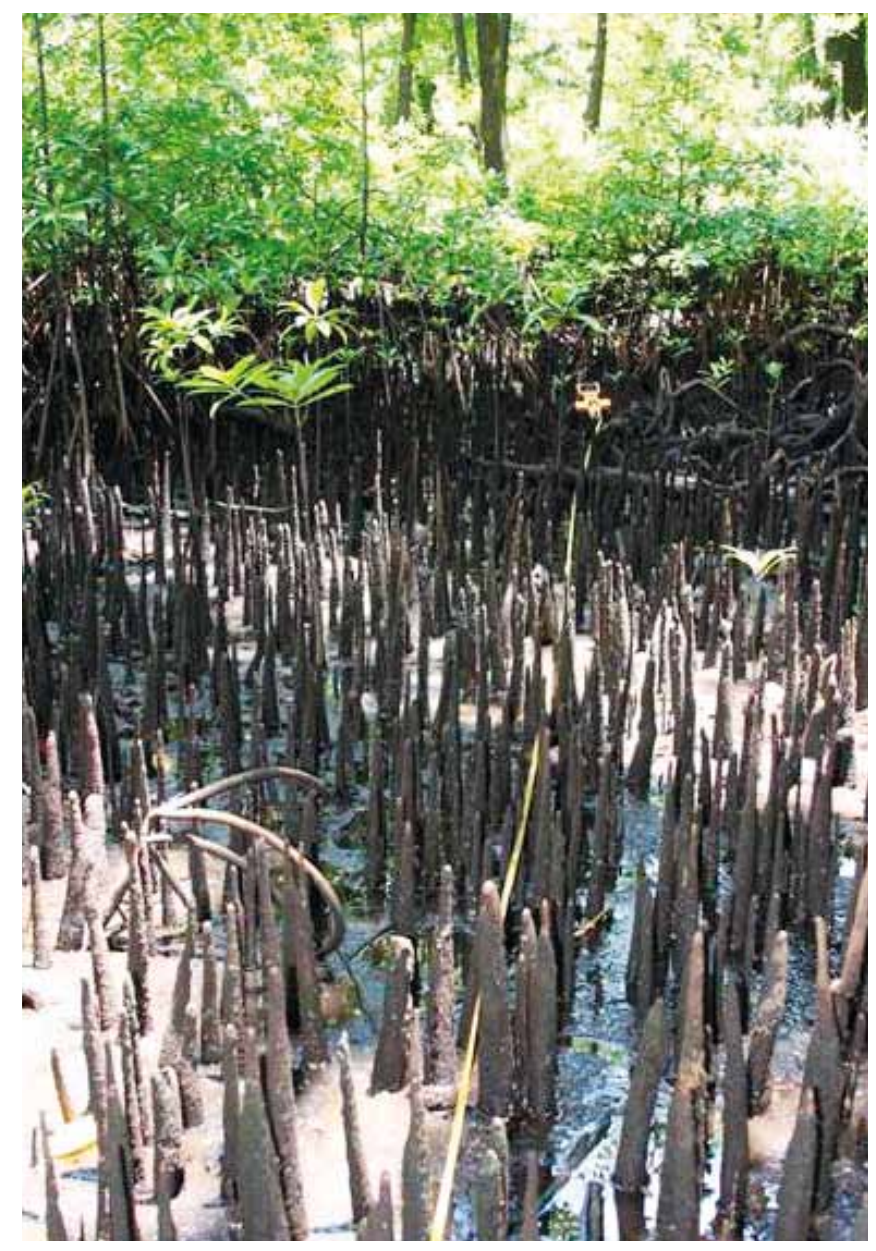

Important rules in measuring downed wood include:

- Dead trees that are standing are not measured in the line intersect. Downed wood must have broken off the tree. Dead branches and stems still attached to standing trees or shrubs do not count.

- The transect tape must intersect the central axis of the piece for it to be counted. This means that if the tape only intersects a corner at the end of a $\log$, it does not count.

- Any piece may be recorded multiple times if the tape intersects it more than once (e.g. a curved piece, or at both the branch and the stem of a fallen tree).

- In a practical sense, only large wood fractions $(>2.5 \mathrm{~cm})$ are usually significant carbon pools (Kauffman and Cole 2010, Kauffman et al. 2011). If sampling the litter component, it may be simpler to include the smaller wood pieces
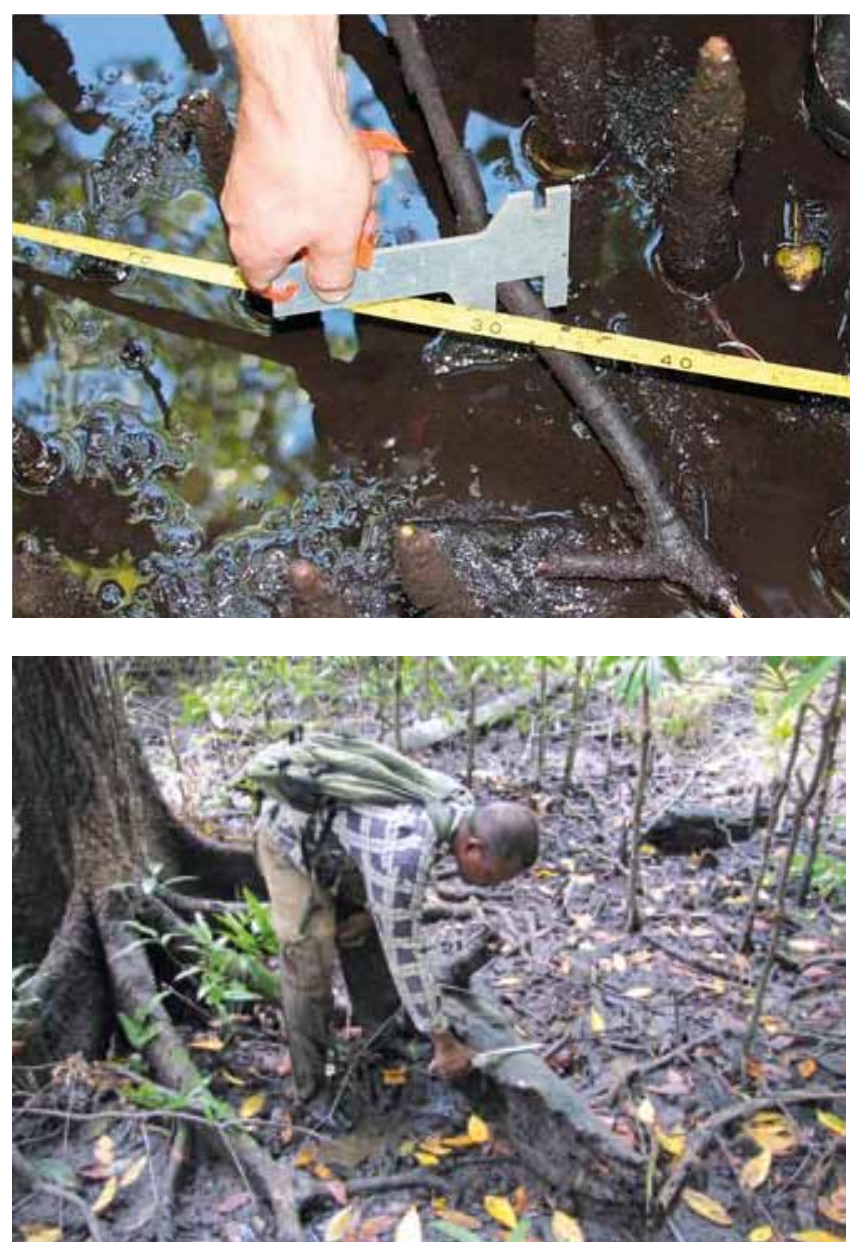

Figure 18. Example of a downed wood transect in a mangrove (left), and measurements of different downed wood size-classes (right) (Photos by Dan Donato/University of Wisconsin and J.B. Kauffman/Oregon State University)

Notes: The upper right is the measurement of fine wood with a wood gauge. The lower right is the measurement of large wood with a folding ruler. 
$(<2.5 \mathrm{~cm}$ diameter) in the litter sample, and only measure the large wood pieces $(>2.5 \mathrm{~cm}$ diameter) in the transects.

\subsubsection{Soil}

Belowground carbon is often the largest pool in a mangrove ecosystem and measuring it is important in determining long-term dynamics associated with climate change and/or land management. Belowground carbon pools usually constitute over $50 \%$, and sometimes over $90 \%$, of the total ecosystem carbon stock of mangroves (Donato $e t$ al. 2011, Kauffman et al. 2011; Figure 3). Despite the importance of soil carbon pools, they are the least studied pools in mangrove forests. This is likely due to the difficulty in obtaining accurate estimates and the recent recognition of the importance of mangroves as global carbon stocks (Lafolley and Grimsditch 2009, Nellemann et al. 2009, Donato et al. 2011).

Organic soils of wetlands are different from mineral soils of uplands, and are frequently difficult to collect. No single methodology or sampling device for soil collection can be recommended as superior to others, since soils vary so greatly in mineral contents and depth (Burton and Pregitzer 2008).

To accurately measure the soil carbon pool, three parameters must be quantified: 1) soil depth;2) soil bulk density; and 3) organic carbon concentration. Careful consideration is essential regarding the number of samples, the location of sampling within the plot, and the depths of sample collection. Given the difficulties and costs associated with soil sampling, the goal is to collect the minimum number of samples necessary to provide an accurate assessment of belowground pools. Recent studies in mangroves have found this to be as few as six samples per site, with multiple depths collected at each point (Figure 6; Kauffman et al. 2011, Donato et al. 2011). The depth to which mangrove soils are sampled is an important decision. Ideally, the entire depth to bedrock (parent materials) or coral sands should be sampled. Mangroves often have organic-rich soils with organic horizons ranging in depth from $0.10 \mathrm{~m}$ to $>3 \mathrm{~m}$. Many carbon assessments of upland forests have limited sampling to the top $30 \mathrm{~cm}$, since most soil carbon is in the top horizons, and this is the most vulnerable to land-use change. However, land-use and climate change will likely affect deeper layers in mangroves due to drainage, oxidation, collapse and sea level rise, etc. (see Hoojier et al. [2006] for similar effects in organic-soils of peatland forests). Therefore, it is recommended that when mangrove soils are deeper than $1 \mathrm{~m}$, at least the top $100 \mathrm{~cm}$ are sampled. For comparisons with other ecosystems, the soil profile should minimally be sampled at 0-30 $\mathrm{cm}$ depth, plus additional samples representing the $30-100 \mathrm{~cm}$ depth range. Kauffman et al. (2011) and Donato et al. (2011) sampled mangrove soils at depths of 0-15 cm, 15-30 cm, 30-50 cm, 50-100 $\mathrm{cm}$, and $>100 \mathrm{~cm}$. They suggested this provided a good partitioning of the belowground pool. At depths of $>100 \mathrm{~cm}$, soil samples are recommended to be collected at a maximum of $2 \mathrm{~m}$ intervals (i.e. samples for nutrient concentrations and bulk density are collected every $2 \mathrm{~m}$, at depths partitioned as 100 $300 \mathrm{~cm}, 300-500 \mathrm{~cm}$, etc.).

The first step in mangrove soil sampling is to measure depth to parent materials, bedrock, or coral sands. It may be quite difficult or impossible to reach these layers in the deep sediments of many riverine mangroves, where alluvial sediments may exceed 5 $m$ in depth. In coastal mangroves over coral sands or bedrock it is feasible to accurately measure soil depth with a probe such as a bamboo pole, avalanche probe, soil augur, or steel pole.

Obtaining soil samples for bulk density and carbon analysis requires soil sampling equipment that can obtain a relatively undisturbed soil sample. Specialised augers for organic or peat soils are recommended (Figure 19). Experimentation with different soil sampling equipment in representative sites is recommended to ensure that accurate measurements are possible. At the sampling location, remove the organic litter from the surface. Then steadily insert the auger vertically into the soil until the top of the sampler is level with the soil surface. If the auger will not penetrate to full depth, do not force it, as it may be obstructed by a large root; instead try another location. Once at depth, twist the auger in a clockwise direction a few times to cut through any remaining fine roots. Gently pull the auger out of soil while continuing to twist it, to assist in retrieving a complete soil sample. If an undisturbed sample has not been obtained, clean the auger and try another location. When this occurs, it is important to remember that this is a very common and frustrating part of sampling saturated organic soils! 

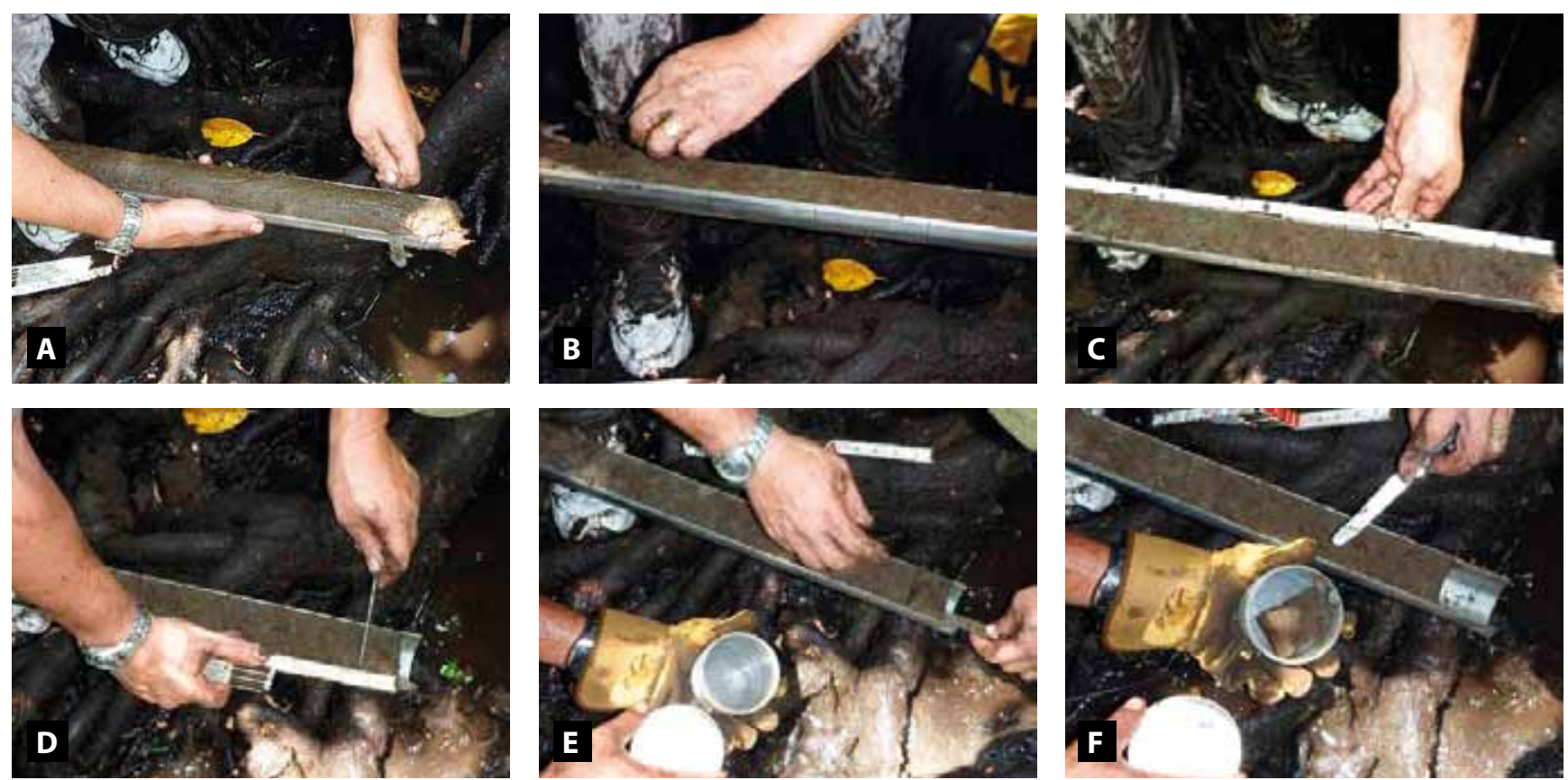

Figure 19. A step by step photos series of the collection of soil samples from an open-face (peat) auger (Photo by Melanie Stidham/US Forest Service)

Notes: A) Cutting the soil away from the auger face; B) cleaned, flat surface of soil core; C) measuring and marking the depth intervals; D) cutting a sample; E) removal of sample from auger; F) collection of sample in numbered container.

Once an undisturbed soil core has been extracted, a ruler or tape measure can be used to determine the depths from which the samples are collected. Subsamples representing a given depth range are generally adequate for mangroves (versus collecting the entire range) because carbon content generally changes much more slowly with depth than in upland forests (Donato et al. 2011, Donato et al 2012, Kauffman et al. 2011). Subsample sizes are usually about a $5 \mathrm{~cm}$ length of the extracted core and comprise at least 30-50 g of sample mass. Subsamples should be collected at the approximate midpoint of each sample depth. For example, the $0-15 \mathrm{~cm}$ sample would ideally come from $5-10 \mathrm{~cm}$ depth; the $50-100 \mathrm{~cm}$ sample would be collected at $72.5-77.5 \mathrm{~cm}$ depth, the $100-300 \mathrm{~cm}$ sample would come from the $197.5-202.5 \mathrm{~cm}$ depth, etc.
For maximum efficiency, a single sample can be collected for both bulk density and carbon analysis (and any other laboratory nutrient or elemental determinations). Upon collection, samples are carefully placed in a numbered soil container with the site, plot number, soil depth, date and any other relevant information recorded.

Upon collection in the field, samples should be ovendried as soon as is practical. If possible, place samples in a drying oven on the day of collection. If this is not possible, as may be the case when sampling in remote areas, it is recommended that samples be air dried to slow microbial activity. Soil samples collected in remote settings can also be sealed in vacuum bags to protect and preserve them. 


\section{Laboratory and data analysis}

\subsection{Biomass and carbon pools of vegetation}

To determine the carbon pool of aboveground components, it is necessary to first determine the biomass of each component of the forest (e.g. large trees, small trees, palms, downed wood, etc.; Figure 4). Carbon pools of aboveground biomass are then determined by multiplying the biomass of individual components by their specific carbon concentration (percentage). To determine the carbon concentration of aboveground biomass, samples of each component can be analysed via dry combustion (i.e. using an elemental analyser). If this is not practical, published carbon concentrations may be used. For example, Kauffman et al. (2011) reported the carbon concentration of the wood of Bruguiera gymnorrhiza as $46.3 \%$, Rhizophora apiculata as $45.9 \%$, and Sonneratia alba as $47.1 \%$. Since the carbon concentration of wood is usually a little less than $50 \%$, it is also common practice to convert biomass to carbon by multiplying by $0.46-0.5$, if local or species-specific values are not available.

\subsubsection{Live trees}

To determine the biomass of trees, published allometric equations are widely applied (Chave $e t$ al. 2005), and mangroves are no exception. Such methods involve establishing a relationship between the biomass of whole trees (or their components) and readily measured parameters, such as main stem diameter, species, and tree height. Main stem diameter is usually expressed as the diameter at $1.37 \mathrm{~m}$ above the ground (dbh), or in the case of Rhizophora, the diameter above the highest stilt root. Because mangroves typically have few species present, species can usually be identified with on-site training. Species identification is important, as it allows the use of species-specific allometric equations for each measured individual. Height is also a common parameter for allometric equations. However, accurate height measurement in the field is difficult and thus not recommended as a parameter, unless collected for other purposes.

A number of publications report allometric equations for mangrove biomass (e.g. Saenger 2002, Chave et al. 2005, Smith and Whelan 2006, Komiyama et al. 2008, Kauffman and Cole 2010) and examples are found in tables 3 and 4. Equations exist for individual species, as well as general equations for mangrove species. Before deciding which biomass equation to use, consider the geographic origin and species that composed the data set from which the equation was derived. Ideally, a species-specific equation developed in the region where the sampling is to occur should be used. Given the differences in structure and wood density among species, speciesspecific equations are likely to yield greater accuracy than general equations. Wood density, morphology and height-diameter relationships vary a great deal between sites, which can affect the accuracy and utility of any equation. It is also critical to note the maximum diameter from which the equation was derived, as applying the equation to larger trees can lead to significant errors (i.e. the biomass of large trees may be overestimated).

Different equations can yield very large differences in biomass predictions (Figure 20). For trees $<20$ $\mathrm{cm}$ dbh differences in biomass estimates are not very great. However, differences in estimates of biomass of the largest individuals (i.e. those with the largest $\mathrm{dbh}$ ) can be dramatic. Figure 20 shows predictions generated from different allometric equations using the same dataset from a mangrove stand in Yap, FSM (Kauffman et al. 2011). For example, the biomass prediction of the largest Bruguiera tree in this mangrove forest $(69 \mathrm{~cm} \mathrm{dbh})$ was $2588 \mathrm{~kg}$ using the Kauffman and Cole (2010) equation, and $7014 \mathrm{~kg}$ using the general equation of Komiyama et al. (2008). Similarly, the biomass estimate for a 45 $\mathrm{cm}$ dbh Sonneratia alba tree was $873 \mathrm{~kg}$ using the Kauffman and Cole (2010) formula but $>1500 \mathrm{~kg}$ using the other equations. For the largest trees in this stand the differences were even more dramatic. The biomass estimate for an $80 \mathrm{~cm}$ dbh tree was $3034 \mathrm{~kg}$ using the Kauffman and Cole (2010) equation, but over 3-fold higher $(9434 \mathrm{Kg})$ using the Komiyama et al. (2008) general mangrove equation. Only the equations developed by Kauffman and Cole (2010) encompassed the entire range of diameters encountered in the mangrove forest reported in this study (Table 3). These large differences underscore the importance of using the same equations, if 


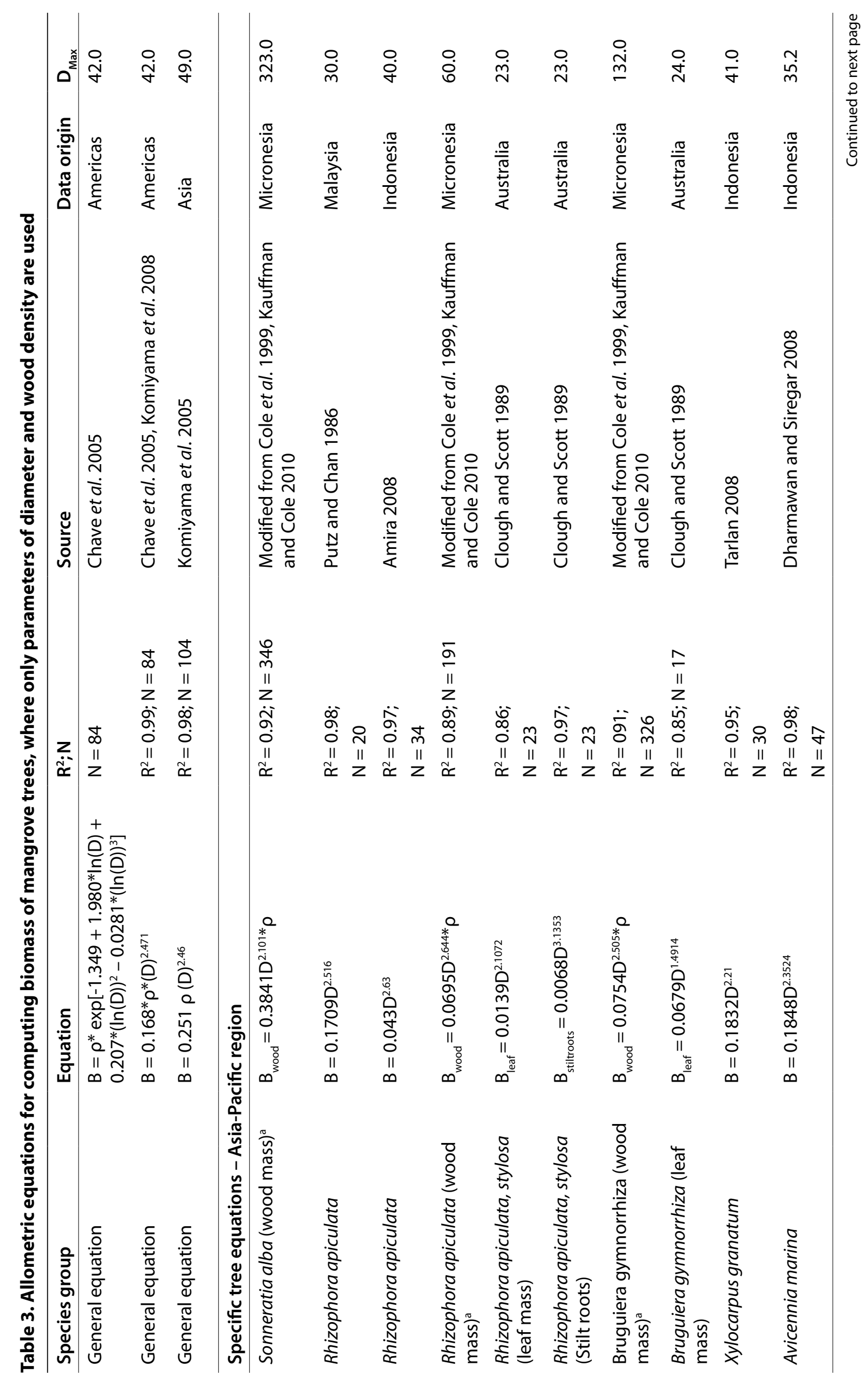




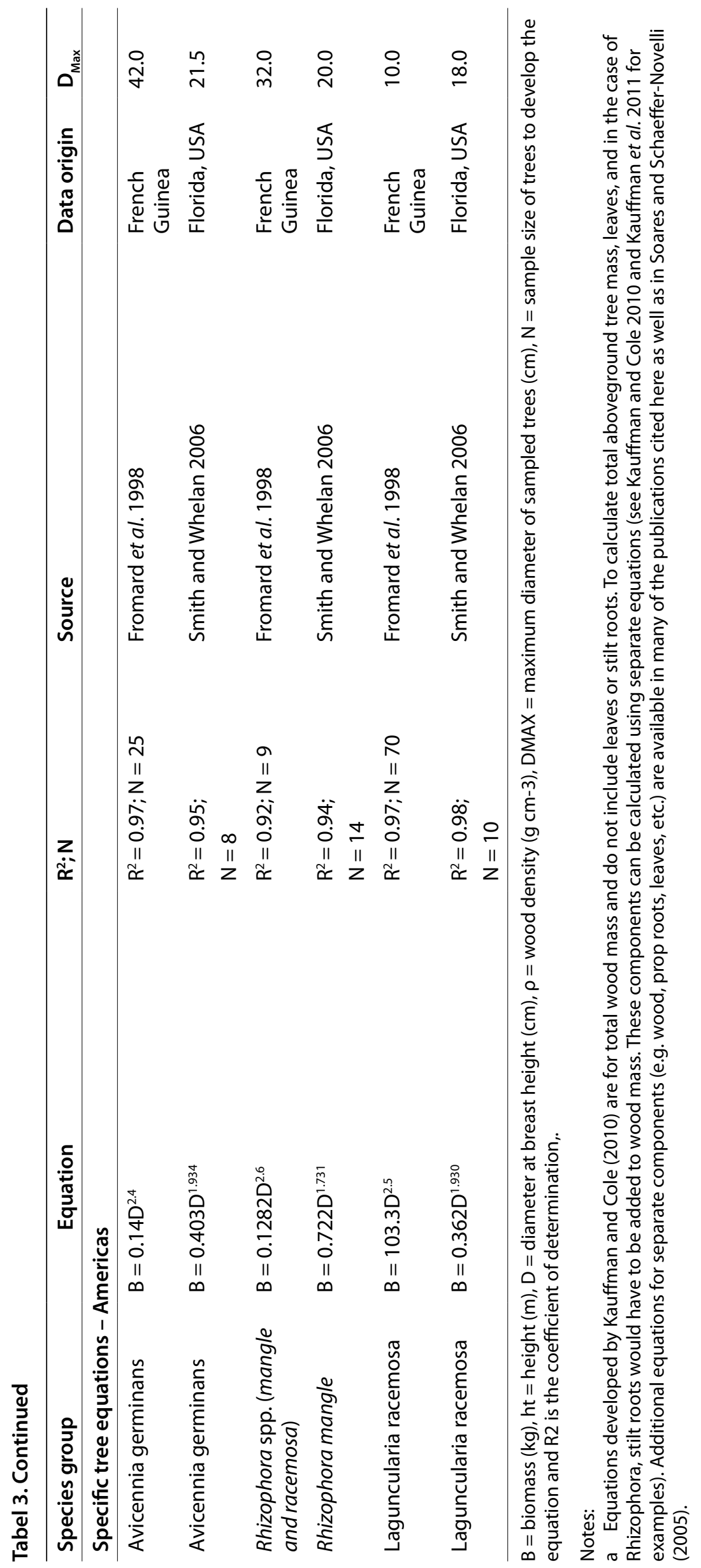




\section{Bruguiera gymnorrhiza}

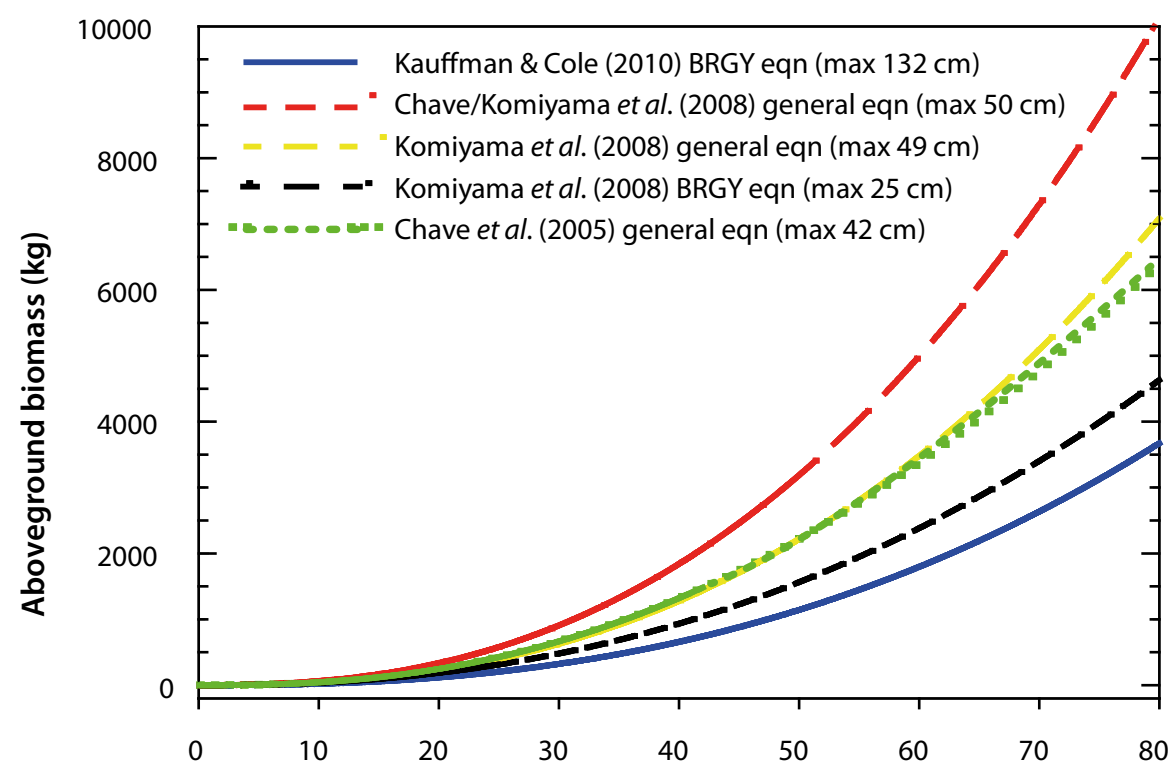

Diameter at breast height $(\mathrm{cm})$

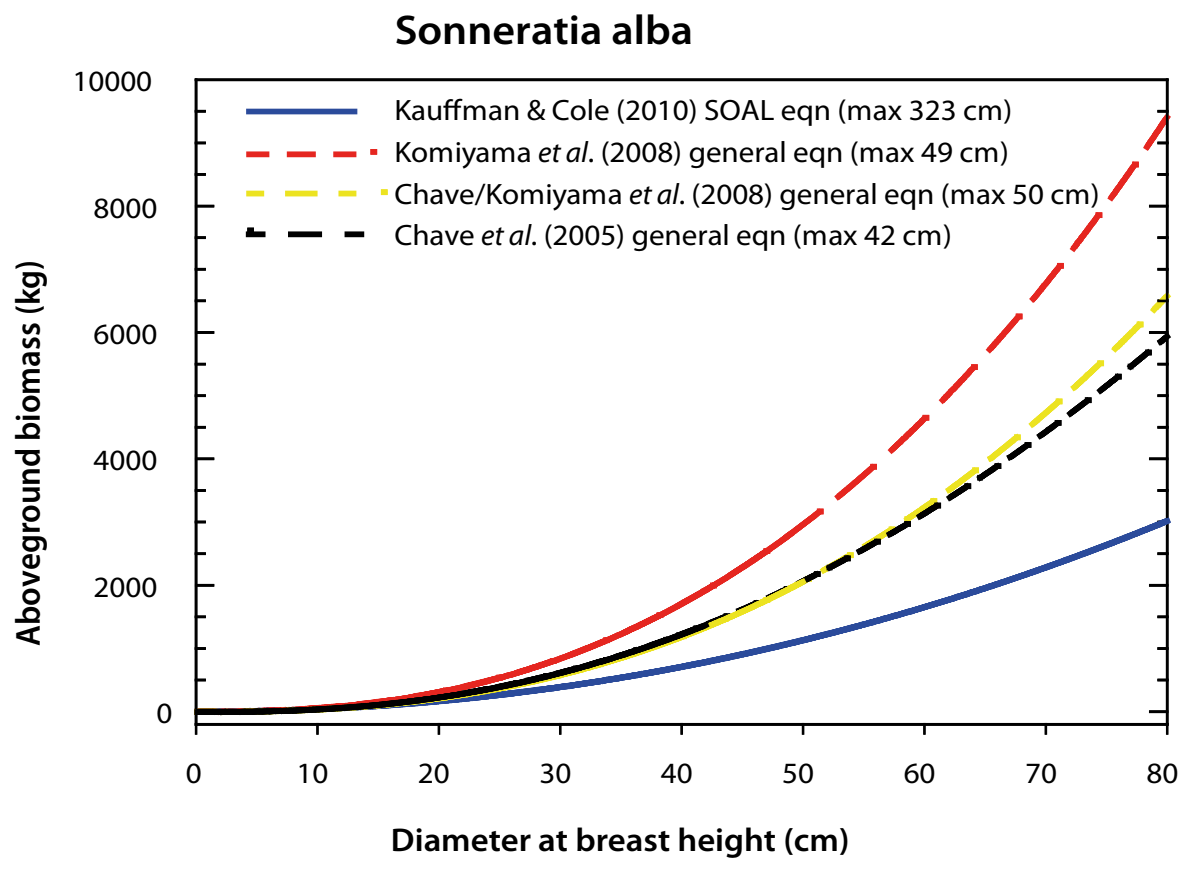

Figure 20. Comparison of tree biomass estimates for Burguiera gymnorrhiza and Sonneratia alba

$\mathrm{BRGY}=$ Burguiera gymnorrhiza, eqn = equation, $\max =$ maximum tree diameter sampled, SOAL = Sonneratia alba.

Note: The numbers in parentheses are the maximum tree diameters used to develop the equations. Dashed portions of curves represent extrapolation beyond the sample range with which an equation was built.

Source: Based on equations developed by Kauffman and Cole (2010), Chave et al. (2005), Komiyama et al. (2008) 
Table 4. Allometric equations using tree height and diameter for computing biomass of mangrove trees

\begin{tabular}{|c|c|c|c|c|c|}
\hline & $\mathbf{N}$ & $\mathrm{D}_{\mathrm{MAX}}$ & Max H & Equation & $\mathrm{R}^{2}$ \\
\hline General equation & 84 & 42.0 & & $B=0.0509 * \rho *(D)^{2} * H$ & \\
\hline Bruguiera gymnorrhiza & 325 & 132.0 & 34 & $0.0464 *\left(D^{2} H\right)^{0.94275 *} \rho$ & 0.96 \\
\hline Sonneratia alba & 345 & 323.0 & 42 & $0.0825 *\left(D^{2} H\right)^{0.89966 *} \rho$ & 0.95 \\
\hline Rhizophora apiculata & 193 & 60.0 & 35 & $0.0444 *\left(D^{2} H\right)^{0.96842 *} \rho$ & 0.96 \\
\hline Rhizophora mucronata & 73 & 39.5 & 21 & $0.0311 *\left(D^{2} H\right)^{1.00741 *} \rho$ & 0.95 \\
\hline Rhizophora spp. & 265 & 60.0 & 35 & $0.0375 *\left(D^{2} H\right)^{0.98626 *} \rho$ & 0.95 \\
\hline Lumnitzera littorea & 20 & 70.6 & 19 & $0.0214 *\left(D^{2} H\right)^{1.05655 *} \rho$ & 0.93 \\
\hline Xylocarpus granatum & 115 & 128.5 & 31 & $0.0830 *\left(D^{2} H\right)^{0.89806 *} \rho$ & 0.95 \\
\hline Rhizophora mangle & 26 & 15.4 & 11 & $125.9571\left(\mathrm{D}^{2} \mathrm{H}\right)^{0.8557}$ & 0.99 \\
\hline
\end{tabular}

$\mathrm{B}=$ biomass $(\mathrm{kg}), \mathrm{H}=$ height $(\mathrm{m}), \mathrm{D}=$ diameter at breast height $(\mathrm{cm}), \rho=$ wood density $(\mathrm{g} \mathrm{cm}-3), D_{\text {MAX }}=$ maximum diameter of sampled trees $(\mathrm{cm})$ and $\mathrm{Max} \mathrm{H}=$ maximum height of sampled trees.

Notes: Parameters of diameter ( $\mathrm{dbh}$ ) and height are used for species-specific equations, and diameter and wood density are used for the general equation.

The general equation is from Chave et al. (2005), and includes all aboveground biomass. Individual species equations were modified from volume equations in Cole et al. (1999). These are equations of total wood mass and do not include leaves or stilt roots. To calculate total aboveground tree mass using these equations, leaves, and in the case of Rhizophora, stilt roots would also have to be calculated using separate equations such as those provided by Clough and Scott (1989). The equation for Rhizophora mangle is from Cintron and Schaeffer-Novelli (1984) and is suitable for use in dwarf mangroves. Additional equations for structural features of this species can be found in this manuscript.

Additional equations can be found in Komiyama et al. (2008), and Smith and Whelan (2006)

possible, when comparing different mangroves and especially the same mangrove stand through time. The former is particularly important for mitigation strategies such as REDD+.

Wood densities for live trees (which may be different from densities of downed woody debris) are required for many biomass equations, including the general mangrove equations. Wood density of individuals of the same species has been shown to vary greatly between sites. As such, it is desirable to use sitespecific wood densities, if possible. Wood densities (specific gravity) may be known by local forest agencies, or can easily be collected and calculated for sample sites. Otherwise, general sources for wood density include the World Agroforestry database (World Agroforestry Centre 2011), as well as Hidayat and Simpson (1994) and Simpson (1996). Table 5 shows wood densities for common mangrove species.

\subsubsection{Belowground tree biomass}

Belowground biomass is an important component in mangroves because it comprises a relatively high proportion of the ecosystem compared to upland forests (Komiyama et al. 2008). It is beyond the
Table 5. Examples of wood density for common mangrove species

\begin{tabular}{lc}
\hline Scientific name & $\begin{array}{c}\text { Wood density } \\
\left(\mathbf{g ~ c m}^{-3}\right)\end{array}$ \\
\hline Bruguiera gymnorrhiza & 0.741 \\
Rhizophora apiculata & 1.050 \\
Rhizophora mangle & 0.830 \\
Sonneratia alba & 0.078 \\
Avicennia germinans & 0.661 \\
Laguncularia racemosa & 0.600 \\
Avicennia officinalis & 0.670 \\
Bruguiera gymnorrhiza & 0.860 \\
Ceriops decandra & 0.960 \\
Excoecaria agallocha & 0.450 \\
Heritiera fomes & 1.074 \\
Sonneratia apetala & 0.559 \\
Xylocarpus granatum & 0.700 \\
Xylocarpus mekongensis & 0.725 \\
Site average of above values & 0.752 \\
\hline
\end{tabular}

Source: Values are from Simpson (1996), and the World Agroforestry Centre (2011) 
capacity of most projects to destructively harvest or measure belowground biomass or develop allometric equations, given the extreme difficulty of their collection and measurement - especially in mangroves. Very few allometric equations exist for belowground biomass of forests, and mangroves are among the least studied forests in this respect. Dharamawan and Siregar (2008) provided a belowground biomass equation for Avicennia marina in Indonesia. Additional studies would be a valuable contribution to science. Useful belowground equations available for mangroves have been reviewed in Komiyama et al. (2008). The general equation reported by Komiyama et al. (2008) is:

$\mathrm{B}_{\mathrm{TB}}=0.199 * \rho^{0.899 *}(\mathrm{D})^{2.22}$

$B_{T B}=$ Tree belowground biomass $(\mathrm{kg}), p=$ wood density $\left(\mathrm{g} / \mathrm{cm}^{3}\right)$, $D=$ tree diameter at breast height $(\mathrm{cm})$.

The carbon mass of roots is calculated as the product of root biomass and root carbon concentration. Carbon concentrations of roots are typically lower than that of aboveground tree components. For example Jaramillo et al. (2003a) reported carbon concentration of roots in tropical forests as 36$42 \%$. A defensible default value for root carbon concentration would be 39\%. The results should be scaled to a per-hectare basis to report carbon pool estimates.

\subsubsection{Standing dead trees}

The biomass of standing dead trees may be determined in two different ways, corresponding to different decay status categories. The biomass of recently dead trees (Decay Status 1: those with fine braches still attached; Figure 13) can be estimated using live tree equations. The only difference is that leaves should be subtracted from the biomass estimate. This can be accomplished either using a leaf biomass equation to determine the quantity of leaves to be subtracted (Clough and Scott 1989, Komiyama et al. 2005, Smith and Whelan 2006) or by subtracting a constant of $2.5 \%$ of the aboveground biomass estimate of the tree. The biomass of Status 2 dead trees can be calculated in a similar manner, subtracting a portion of the biomass; however, because they have also lost some branches in addition to leaves, both leaf biomass and an estimate of branch loss must be factored in. Commonly, a total of $10-20 \%$ of biomass (accounting for both leaves and some branches) is subtracted. This amount can be adjusted and tailored to specific settings using local knowledge.

Different approaches are required for dead trees in later stages of decay. Decay Status 3 trees (Figure 13) have often lost a significant portion of their volume due to advanced breakage, and these variable losses are difficult to subtract from the live-tree biomass estimates. Instead, the remaining tree's volume may be calculated using an equation for a frustum (truncated cone). To do this, the top diameter must be estimated with a taper equation, using the basediameter and height measurements that are taken in the field for Status 3 trees.

The taper equation for estimating the top-diameter of a broken-topped dead tree is as follows:

$\mathrm{d}_{\text {top }}=\mathrm{d}_{\text {base }}-\left[100 * h t *\left(\frac{\left(\mathrm{d}_{\text {base }}-\mathrm{dhb}\right)}{130}\right)\right]$

$d_{\text {top }}=$ estimated diameter at top of tree $(\mathrm{cm}), d_{\text {base }}=$ the measured basal diameter $(\mathrm{cm}), \mathrm{ht}=$ tree height $(\mathrm{m}), \mathrm{dbh}=$ diameter at breast height $(\mathrm{cm})$.

Next, volume is determined as follows, by assuming the tree is a truncated cone:

$\operatorname{Volume}\left(\mathrm{cm}^{3}\right)=\left(\frac{\pi^{*}\left(100^{*} \mathrm{ht}\right)}{12}\right) *\left(\mathrm{~d}_{\text {base }}^{2}+\mathrm{d}_{\text {top }}^{2}+\left(\mathrm{d}_{\text {base }} * \mathrm{~d}_{\text {top }}\right)\right)$

$h t=$ tree height $(m), d_{\text {base }}=$ the basal diameter $(\mathrm{cm}), d_{\text {top }}=$ the diameter at the top $(\mathrm{cm})$ estimated from the taper equation (if taper equation results in a negative number, use 0 for $\mathrm{d}_{\text {top }}$ ).

Dead tree biomass $(\mathrm{g})$ is then determined by multiplying volume $\left(\mathrm{cm}^{3}\right)$ by wood density $\left(\mathrm{g} \mathrm{cm}^{-3}\right)$. The wood density of standing dead trees needs to be determined. The wood density of downed wood (see Table 6) could be used for this determination.

Dead tree biomass can be converted to carbon mass using a locally derived concentration of carbon if available. The carbon concentration of dead wood is usually around 50\% (e.g. Kauffman et al. 1995) and a default value for carbon concentrations of dead trees could be 0.50 . The results should be scaled to a per-hectare basis to report carbon pool estimates. 
Table 6. The specific gravity and mean diameter of the standard wood debris size classes of downed mangrove wood used to estimate wood mass

\begin{tabular}{llcllc}
\hline $\begin{array}{l}\text { Size class } \\
\text { (cm diameter) }\end{array}$ & $\begin{array}{l}\text { Specific gravity } \\
\pm \text { SE }\end{array}$ & Sample size & Diameter $(\mathbf{c m})$ & $\begin{array}{l}\text { Quadratic mean } \\
\text { diameter }(\mathbf{c m})\end{array}$ & Sample size \\
\hline$<0.64$ & $0.48 \pm 0.01$ & 117 & $0.43 \pm 0.15$ & 0.43 & 50 \\
$0.65-2.54$ & $0.64 \pm 0.02$ & 31 & $1.33 \pm 0.78$ & 1.47 & 48 \\
$2.55-7.6$ & $0.71 \pm 0.01$ & 69 & $4.30 \pm 0.18$ & 4.52 & 52 \\
$>7.6$ & $0.69 \pm 0.02$ & 61 & na & na & na \\
\hline
\end{tabular}

na $=$ not applicable, $\mathrm{SE}=$ standard error.

Notes: Downed wood is a composite sample from mangrove forests dominated by Rhizophora apiculata, Sonneratia alba and Bruguiera gymnorrhiza.

In this technique the diameter of all pieces of wood in this size class is measured. The wood density information in Table 6 was derived from downed wood measured following a typhoon, with little to moderate decay. In an Australian Rhizophora-dominated mangrove forest, Robertson and Daniel (1989) reported moderately to very decomposed downed wood densities to range from; twigs $0.628-0.350$; branches $0.60-0.284$; prop roots $0.276-0.511$; and trunks $0.340-0.234$. These roughly correspond to the size classes above. The broad differences in these two studies demonstrate the need for site-specific estimations of downed wood density.

Source: Data from Kauffman and Cole (2010)

\subsubsection{Lianas}

A number of equations to determine liana biomass exist (Schnitzer et al. 2006). Liana biomass can be estimated using the following general allometric equation:

$\mathrm{B}=\mathrm{D}^{2.657 *} \mathrm{e}^{-0.968}$

* In(D)

$\mathrm{B}=$ biomass $(\mathrm{kg}), \mathrm{D}=$ the diameter $(\mathrm{cm})$ of the liana measured $130 \mathrm{~cm}$ from the root-soil surface interface, $R^{2}=0.69, N=424$ (Schnitzer et al. 2006).

A general equation for lianas in tropical uplands of China is presented by Lu et al. (2009):

$\mathrm{B}=0.1498+1.7895^{*} \operatorname{In}(\mathrm{D})^{*} \operatorname{In}(\mathrm{D})$

$\mathrm{B}=$ biomass $(\mathrm{kg}), \mathrm{D}=$ the diameter $(\mathrm{cm})$ of the liana $130 \mathrm{~cm}$ from the root-soil interface, $R^{2}=0.87, N=25$ (Lu et al. 2009).

Liana biomass can be converted to carbon mass using a locally derived carbon concentration if available. The carbon concentration of lianas in tropical forest uplands has been reported to be about $46 \%$ (e.g. Jaramillo et al. 2003b). A default value for carbon concentrations of lianas could be 0.46 . The results should be scaled to a per-hectare basis to report carbon pool estimates.

\subsubsection{Forest floor vegetation and litter}

Understory vegetation (e.g. seedlings and herbs) is generally negligible in mangroves and its measurement for ecosystem carbon pools is usually unnecessary. Nypa palm can be quite significant in stands where it may be the sole dominant. For nipa palm, mass can be calculated using the mean mass per leaf times the leaf density. Converting to carbon mass would entail multiplying mass by the carbon concentration, which has been reported to be about $47 \%$ for palms (Kauffman et al. 1998).

Litter is also a small component of the total ecosystem carbon stock and therefore not usually sampled. If it is measured, the total oven-dry mass of the subplot area (e.g. $50 \times 50 \mathrm{~cm}$ ) must be scaled to a per-hectare estimate. Mean carbon concentrations of tropical forest leaf litter have been reported as 38-49\% (Kauffman et al. 1993, 1995). A conversion factor of about 0.45 is recommended.

\subsubsection{Dead and downed wood}

Using the line intercept technique to measure downed wood $<7.6 \mathrm{~cm}$ diameter (i.e. fine, small and medium classes defined in Table 2) entails converting counts of these size classes into biomass. This approach requires collection to determine the average diameter of wood particles in each of these classes, as 
well as the density or specific gravity of the downed wood. The average diameter of wood particles can be derived from measurements of about 50-100 randomly selected particles of each size class in the field. A digital caliper is recommended for these measurements. Use of the quadratic mean diameter (QMD) of the wood particles is recommended to calculate volume rather than the mean diameter of wood classes (Brown and Roussopolous 1974). The QMD is calculated as follows:

$\mathrm{QMD}=\sqrt{\frac{\left(\sum \mathrm{d}_{\mathrm{i}}^{2}\right)}{\mathrm{n}}}$

$d_{i}=$ the diameter of each sampled piece of wood in the size class, $\mathrm{n}=$ the total number of pieces sampled.

Specific gravity must also be determined for each wood category sampled (fine, small, medium, largesound, large-rotten). It is recommended that at least 20-25 pieces are collected for each size class, capturing a representative range of sizes, and the full range of species present in the sample. As a rough guideline, each piece collected for specific gravity determination should have a mass of about $0.5-50$ g. Pieces for determination of specific gravity should be randomly collected within the project area but not inside permanent sample plots to avoid undue disturbance. Specific gravity requires measurement of both oven-dry mass and volume of each sampled piece. Volume is obtained via determination of each piece's submerged mass. This is accomplished by placing a water container on a digital balance of a size sufficient to submerge each piece. Each piece of sampled wood is attached to a needle that is attached to a ring stand above the scale. The piece is then submerged (without touching the bottom and sides of the container) and the change in mass is recorded.
Because the specific gravity of water is $1 \mathrm{~g} \mathrm{~cm}^{-3}$, the resultant increase in mass shown on the scale is the volume displaced by the particle. To obtain specific gravity, the mass of each piece is divided by volume, then the mean for each size class is computed. These mean values will be used in later computations of biomass and/or carbon. Examples of QMD and specific gravity of downed wood from mangrove forests are shown in Table 6 .

Downed wood volume is then calculated from line intercept data using scaling equations.

The following equation is used to determine volume of fine, small and medium wood size classes:

$\operatorname{Volume}\left(\mathrm{m}^{3} h \mathrm{a}^{-1}\right)=\pi^{2 *}\left(\frac{\mathrm{N}_{i}{ }^{*} \mathrm{QMD}_{\mathrm{i}}^{2}}{8^{*} \mathrm{~L}}\right)$

$N_{i}=$ the count of intersecting woody debris pieces in size class $i$, $\mathrm{QMD}_{\mathrm{i}}=$ the quadratic mean diameter of size class $\mathrm{i}(\mathrm{cm})$, $\mathrm{L}=$ transect length $(\mathrm{m})$.

Source: van Wagner (1968), Brown (1971)

The following equation is used for calculating the volume of large $(>7.6 \mathrm{~cm}$ diameter) downed wood (which is individually measured):

Volume $\left(\mathrm{m}^{3} \mathrm{~h}^{-1}\right)=\pi^{2}\left(\frac{\mathrm{d}_{1}^{2}+\mathrm{d}_{2}^{2}+\mathrm{d}_{3}^{2}+\ldots . \mathrm{d}_{\mathrm{n}}^{2}}{8^{*} \mathrm{~L}}\right)$

$d_{1}, d_{2^{\prime}}$ etc. $=$ diameters of intersecting pieces of large dead wood $(\mathrm{cm}), \mathrm{L}=$ the length of the transect line for large size class $(m)$.

Source: van Wagner (1968), Brown (1971)

Table 7. Downed wood mass $\left(\mathrm{Mg} \mathrm{ha}^{-1}\right.$ ) by size class (diameter in $\mathrm{cm}$ ) and condition in mangrove forests, Yap, FSM

\begin{tabular}{|c|c|c|c|c|c|c|}
\hline $\begin{array}{c}\text { Mangrove } \\
\text { Sites }\end{array}$ & $\geq 7.6 \mathrm{~cm}$ sound & $\begin{array}{c}\geq 7.6 \mathrm{~cm} \\
\text { rotten }\end{array}$ & $2.55-7.5 \mathrm{~cm}$ & $\begin{array}{c}0.65-2.54 \\
\mathrm{~cm}\end{array}$ & $\leq 0.64 \mathrm{~cm}$ & Total mass \\
\hline Maaq & $9.80 \pm 5.20$ & $0.30 \pm 0.30$ & $7.90 \pm 0.40$ & $6.00 \pm 1.00$ & $0.10 \pm 0.03$ & $24.10 \pm 5.80$ \\
\hline Qatliw & $14.00 \pm 2.10$ & $0.00 \pm 0.00$ & $9.00 \pm 1.10$ & $8.70 \pm 0.40$ & $0.60 \pm 0.10$ & $32.30 \pm 2.80$ \\
\hline Ruunuw & $42.50 \pm 17.20$ & $0.00 \pm 0.00$ & $8.00 \pm 1.50$ & $5.50 \pm 0.80$ & $0.50 \pm 0.10$ & $56.50 \pm 15.80$ \\
\hline Tabinifiy & $23.30 \pm 6.40$ & $1.80 \pm 1.80$ & $9.80 \pm 0.30$ & $6.70 \pm 0.90$ & $0.20 \pm 0.03$ & $41.70 \pm 6.80$ \\
\hline Qamum & $14.10 \pm 10.10$ & $0.00 \pm 0.00$ & $5.90 \pm 1.10$ & $3.10 \pm 0.90$ & $0.20 \pm 0.10$ & $23.20 \pm 10.30$ \\
\hline Qaaf & $13.90 \pm 3.10$ & $0.30 \pm 0.30$ & $7.50 \pm 1.20$ & $9.00 \pm 1.00$ & $0.40 \pm 0.10$ & $31.10 \pm 4.20$ \\
\hline
\end{tabular}

Note: Data are mean \pm standard error. The mass calculated here used specific gravities and quadratic mean diameters from Table 6. 
Wood biomass is then calculated as the volume multiplied by its mean specific gravity. An example of wood debris mass from Yap, FSM is given in Table 7. Finally, the downed wood biomass is converted to carbon mass. It is advisable to determine the carbon concentration of the wood for this measurement. An acceptable default value, based on carbon concentrations of dead wood in tropical forests, is $50 \%$.

\subsubsection{Soils}

To calculate the mass of carbon in soils it is necessary to know the depth, bulk density and carbon concentration of the soil.

\subsubsection{Bulk density}

On returning from the field, soil samples should be oven-dried to a constant mass at $60^{\circ} \mathrm{C}$. Higher temperatures may reduce the carbon in the sample and should be avoided. In many protocols, drying at $105^{\circ} \mathrm{C}$ is recommended for bulk density determination, to boil away any water from the sample. However, this would require collecting a second sample from each depth interval, since samples to be analysed for carbon should not be exposed to such a high temperature. The authors have determined that mangrove soil bulk density, derived from drying at $60{ }^{\circ} \mathrm{C}$, is within about $1 \%$ of that derived from drying at $105^{\circ} \mathrm{C}$. Given this almost negligible difference, the effort of double sample collection can be avoided. Typically, it requires at least 48 hours for samples to attain a constant dry mass when dried at $60^{\circ} \mathrm{C}$. Caution should be taken to ensure that samples are thoroughly dried before bulk density and carbon analysis. Carefully breaking up the sample into smaller pieces improves the drying process.

Bulk density is determined by dividing the oven-dry soil sample by the volume of the sample. The bulk density equation is as follows:

Soil bulk density $\left(\mathrm{g} \mathrm{cm}^{-3}\right)=\frac{\text { Oven-dry sample mass }(\mathrm{g})}{\text { Sample Volume }\left(\mathrm{m}^{3}\right)}$

\subsubsection{Soil carbon concentration}

Soil samples should be sent to a reliable and experienced laboratory for analysis. It is recommended that the selected laboratory be checked to ensure that they follow commonly accepted standard procedures with respect to sample preparation and carbon analysis methods. Dry combustion with an elemental analyser and wet combustion are the two basic approaches used to quantify total carbon in soils (Nelson and Sommers 1996, Schumacher 2002). Dry combustion is the most suitable method for routine analysis of total carbon (Sollins et al. 1999). This method uses a high temperature induction furnace. Wet combustion via the Walkley-Black method is also commonly used because it is simple and requires minimal equipment. However, the results obtained cannot be considered quantitative (Nelson and Sommers 1996), and the process also produces toxic wastes (Sollins et al. 1999). Another method that is not quantitative, albeit rapid, is the loss on ignition (LOI) method, which determines soil organic matter through combustion of the soil sample at high temperatures (Nelson and Sommers 1996). Total carbon in peats can then be calculated as the organic matter concentration (percentage) divided by $1.86-1.89$ (Nelson and Sommers 1996). Given its serious shortcomings, the LOI method should be checked against the dry combustion method for accuracy and correction. In organic soils in Palau mangroves, we found that the mean carbon concentration could be determined by dividing organic matter concentration by 2.06. However, the range in the ratio of organic matter to carbon concentration was $1.33-2.80$, suggesting the possible errors in using LOI. We found a positive, yet not particularly strong

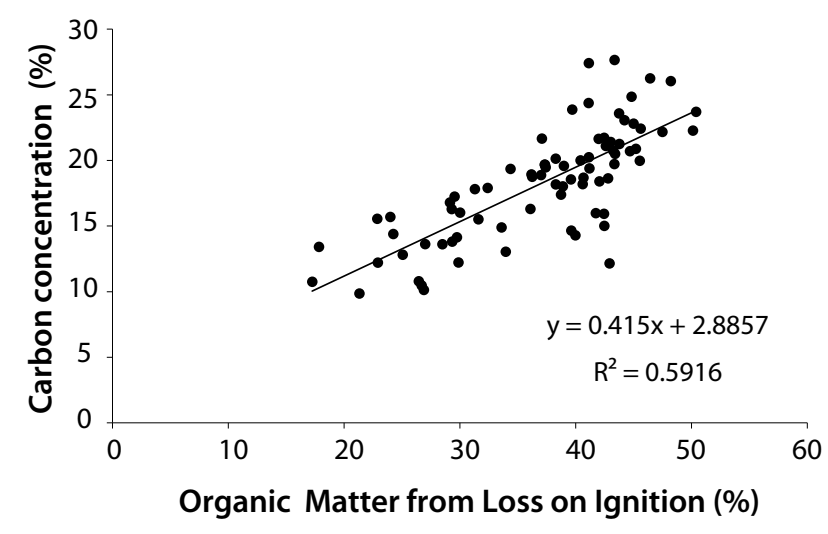

Figure 21. The relationship between organic matter (calculated via loss on ignition) and carbon concentration (percentage) (calculated via dry combustion) for mangrove soil samples from the Republic of Palau

Note: Carbon concentrations and pools for this site can be found in Kauffman et al. (2011) 
relationship $\left(r^{2}=0.59\right)$ between the organic matter determined via LOI and the carbon concentration via dry combustion (Figure 21). The regression equation reported in Figure 21 could also be used to predict carbon concentration based upon organic matter content derived from LOI results.

Additional reviews of soil sampling and laboratory processing can be found in Sparks and Bartels (1996), Robertson et al. (1999), Schumacher (2002), and Burton and Pregitzer (2008).

\subsubsection{Calculating soil carbon pools}

Total soil carbon pools are determined by summing the mass of each sampled soil depth. For example, in Table 8 the total soil carbon pool was determined by partitioning the soil horizon into depth intervals of $0-15 \mathrm{~cm}, 15-30 \mathrm{~cm}, 30-50 \mathrm{~cm}, 50-100 \mathrm{~cm}$ and $100-300 \mathrm{~cm}$, and taking measurements of bulk density and carbon concentration at each layer.

The soil carbon mass per sampled depth interval is calculated as follows:

Soil carbon $\left(\mathrm{Mg} \mathrm{ha}^{-1}\right)=$ bulk density $\left(\mathrm{g} \mathrm{cm}^{-3}\right) *$ soil depth interval $(\mathrm{cm}) * 0 \mathrm{C}$

$\% \mathrm{C}$ is the carbon concentration expressed as a whole number.

The total soil carbon pool is then determined by summing the carbon mass of each of the sampled soil depths. Ideally, the entire organic soil carbon pool (to bedrock or coral sands) is accounted for.

\subsection{Total carbon stock or the total ecosystem carbon pool}

The total carbon stock or pool (also sometimes referred to as the carbon density) is estimated by adding all of the component pools. First, each component pool is averaged across all plots (e.g. trees, soil, etc.). These average values are then summed to obtain the total.

The equation for total carbon stock or pool is as follows:

Total carbon stock $\left(\mathrm{Mg} \mathrm{ha}^{-1}\right)$ of the sampled stand $=$ $\mathrm{C}_{\text {treeAG }}+\mathrm{C}_{\text {treeBG }}+\mathrm{C}_{\text {deadtree }}+\mathrm{C}_{\text {sap/seed }}+\mathrm{C}_{\text {sap/sedBG }}+$ $\mathrm{C}_{\text {deadsap/seed }}+\mathrm{C}_{\text {nontreeveg }}+\mathrm{C}_{\text {woodydebris }}+\mathrm{C}_{\text {soil }}$
$\mathrm{C}_{\text {treeAG }}=$ aboveground carbon pools of trees, tree $_{\mathrm{BG}}=$ belowground tree carbon pool, $C_{\text {deadtree }}=$ the dead tree pool, $C_{\text {sap/seed }}=$ saplings and seedling carbon pools, $C_{\text {nontreeveg }}=$ nontree vegetation carbon pools, $C_{\text {woodydebris }}=$ downed wood carbon pool, $C_{\text {soil }}$ is the total soil carbon pool.

The equation for total carbon stock of a given project area is as follows:

Total carbon stock of project area $(\mathrm{Mg})=$ Total carbon $\left(\mathrm{Mg} \mathrm{ha}^{-1}\right) *$ Area (ha).

\subsubsection{Converting to carbon dioxide equivalents}

Greenhouse gas inventories (and emissions) are often reported in units of carbon dioxide $\left(\mathrm{CO}_{2}\right)$ equivalents, or $\mathrm{CO}_{2} \mathrm{e}$. This convention is because $\mathrm{CO}_{2}$ is the most common greenhouse gas form of carbon. Deforestation and forest degradation result in greenhouse gas emissions dominated by $\mathrm{CO}_{2}$, with other trace gases such as $\mathrm{CH}_{4}$ also being released (Guild et al. 2004).

The total carbon density or total carbon stock can be converted to $\mathrm{CO}_{2} \mathrm{e}$ by multiplying carbon density or stock by 3.67. This is the ratio of molecular weights between carbon dioxide [44] and carbon [12]. For example, the four mangrove forests reported in Figure 22 have a $\mathrm{CO}_{2} \mathrm{e}$ of $2074-4621 \mathrm{Mg} /$ ha. These are among the highest carbon pools of any forest type in the world and also among the most vulnerable to the effects of land-use and land-cover change, and global climate change. Reporting in $\mathrm{CO}_{2} \mathrm{e}$ is considered conservative, as carbon losses in the forms of $\mathrm{CH}_{4}$ and other greenhouse gasses have a higher global warming potential than that of $\mathrm{CO}_{2}$.

\subsection{Quantifying uncertainty in carbon pools}

For carbon assessments it is essential that uncertainty is reported for each component pool, as well as total carbon stock. Uncertainty reflects the degree of precision in the dataset (i.e. the degree of variation around the mean value). For carbon assessments it is typically reported as a $95 \%$ confidence interval (CI), expressed as a percentage of the mean. For example, if the value is $100 \mathrm{Mg} \mathrm{ha}^{-1}$ and the $95 \% \mathrm{CI}$ is $90-110 \mathrm{Mg} \mathrm{ha}^{-1}$, the uncertainty in the estimate is $\pm 10 \%$. Key definitions relevant to uncertainty in 
forest carbon inventories can be reviewed in GOFCGOLD (2011).

\subsubsection{Uncertainty in component pools}

The first step is to compute the $95 \%$ CI for each component pool (trees, downed wood, soil, etc.). For practical purposes, the $95 \% \mathrm{CI}$ is the mean plus or minus 2 times the standard error (SE) of the mean. In other words, the $95 \%$ CI half-width $=2 *$ SE.

The $95 \%$ CI half-width is used to express the uncertainty as a percentage of the mean.

Uncertainty $(\%)=100 *(95 \%$ CI half-width $) /$ mean.

\subsubsection{Uncertainty in total stand-level carbon stock}

Total carbon stock is the sum of all the carbon pools (trees, wood, soils, etc.), each of which has its own uncertainty. Calculating uncertainty for the total carbon stock requires accounting for the uncertainty of each of the component pools.

There are two methods for calculating the total uncertainty for carbon stocks (Pearson et al. 2005, 2007, GOFC-GOLD 2011). The first method uses simple error propagation through the square root of the sum of the squares of the component errors. The second method uses Monte Carlo simulations to propagate errors. ${ }^{3}$ The advantage of the first method is that it is simple to use and requires no additional computer software. The second method is used when substantial correlations exist between datasets (for example, between two carbon pools), when uncertainties are very large (e.g. greater than $100 \%$ ), or when data distributions are strongly nonnormal. In theory, it is always better to use Monte Carlo analysis because it is robust to almost any data structure. If data analysts knowledgeable of this method are available, this might be a preferred approach. However, the difference in results attained through the two methods is typically small,

3 The principle of Monte Carlo analysis is to perform the summing of uncertainties many times, each time with the uncertain components chosen randomly by Monte Carlo software from within the distribution of uncertainties entered by the user. Examples of Monte Carlo software include Simetar, @Risk, or Crystal Ball (www.simetar.com, www.palisade.com/ html/risk.asp, www.crystalball.com). The use of trade names does not constitute endorsement by the US government. unless correlations and/or uncertainties are very high (Pearson et al. 2007). Thus, the simple error propagation method is often used and is detailed here for that reason.

Equation for uncertainty in total carbon stock (stand- level):

For the uncertainty of the carbon stock at the standlevel, the formula for the $95 \%$ CI half-width is as follows:

$$
\begin{aligned}
& \text { 95\% CI half }- \text { width for } \\
& \text { total carbon stock }
\end{aligned}
$$

$\left[95 \% \mathrm{Cl}_{\mathrm{cl}}\right]$ is the $95 \% \mathrm{Cl}$ half-width for pool 1, (e.g. tree carbon mass), pool 2, and so on for all pools measured in the plots.

For mangroves we recommend the pools to be aboveground live trees, dead trees, downed wood, belowground plant carbon, and soil carbon. These five pools will likely comprise $>95 \%$ of the true ecosystem carbon stock of mangroves. The total uncertainty in carbon stock can either be expressed as the range about the mean or as a percentage of the mean.

\subsubsection{Uncertainty in total carbon stock of project areas, regions or other large areas}

Quantifying the uncertainty in the carbon stocks of large areas follows the same general concept as calculations for stand-level carbon stock. However, the formula is slightly different because the estimate requires multiplication rather than addition of inputs (see equation for stand-level carbon stock above).

The remote sensing analysis of land cover types (e.g. mangrove forest) should have an uncertainty estimate associated with it. This uncertainty should be combined with the uncertainty in stand-level carbon stock using the following equation (to determine uncertainty in the total carbon stock of a project area):

$$
\begin{aligned}
& \begin{array}{c}
95 \% \text { CI half - width for } \\
\text { carbon stock of } \\
\text { project area }
\end{array}=\text { area } * \text { TCS } * \sqrt{\left(\left[95 \% \mathrm{CI}_{\text {arca }} / \text { area }\right]^{2}+\right.} \\
& \left.\left[95 \% \mathrm{CI}_{\mathrm{TCS}} / \mathrm{TCS}\right]^{2}\right)
\end{aligned}
$$

Area $=$ estimated land area in mangrove (ha), TCS = mean stand-level carbon stock of the mangrove $\left(\mathrm{Mg} \mathrm{ha}^{-1}\right), 95 \% \mathrm{Cl}_{\mathrm{x}}$ $=$ the uncertainty of each parameter (expressed as $95 \% \mathrm{Cl}$ half width). 
For example, if the mangrove is estimated at 400000 $\pm 30000 \mathrm{ha}$, and the total carbon stock is $300 \pm 30$ $\mathrm{Mg} \mathrm{ha}^{-1}$, the total carbon stock over the whole area would be reported as $400000 \mathrm{ha}^{*} 300 \mathrm{Mg}$ ha $(=120$ $000000 \mathrm{Mg}$ ). The uncertainty around this value is computed as follows:

$95 \%$ CI half - width for $=400000 * 300 * \sqrt{([30000 / 400000]}$ total carbon stock $\left.(\mathrm{Mg}) \quad[30 / 300]^{2}\right)$

$$
=15000000 \mathrm{Mg}
$$

$$
\left.[30 / 300]^{2}\right)
$$

Like stand-level carbon stock, the uncertainty in total carbon stock over an area can be expressed as the actual interval, or as a percentage of the mean estimate. 


\section{Reporting}

The final and perhaps most important steps in the inventory are presentation and publication of results in an interpretable manner. Reporting may be as simple as presenting the species composition, biomass and ecosystem carbon pool (aboveground and belowground), as in Figure 3. In contrast, where long-term baselines are needed, it may be desirable to partition the biomass and carbon

Table 8. Examples of carbon pools divided into discrete components of the ecosystem

\begin{tabular}{|c|c|c|c|c|}
\hline & \multicolumn{4}{|c|}{ Location } \\
\hline & $\begin{array}{l}\text { Yap, Federated } \\
\text { States of } \\
\text { Micronesia' }\end{array}$ & $\begin{array}{l}\text { Babeldoab, } \\
\text { Republic of Palau' }\end{array}$ & $\begin{array}{l}\text { Sundarbans, } \\
\text { Bangladesh }^{2}\end{array}$ & Kalimantan, Indonesia ${ }^{3}$ \\
\hline Geomorphic position & Coastal fringe & Coastal fringe & $\begin{array}{l}\text { Large delta - } \\
\text { Ganges River }\end{array}$ & Riverine/estuarine \\
\hline Site dominance & Sonneratia alba & $\begin{array}{l}\text { Rhizophora } \\
\text { apiculata }\end{array}$ & $\begin{array}{l}\text { Heriteria fomes, } \\
\text { Excoecaria } \\
\text { agallocha }\end{array}$ & $\begin{array}{l}\text { Rhizophora apiculata, } \\
\text { Bruguiera gymnorrhiza }\end{array}$ \\
\hline \multicolumn{5}{|l|}{ Live trees } \\
\hline $0-10 \mathrm{~cm} \mathrm{dbh}$ & 0.6 & 6.4 & 8.3 & 2.5 \\
\hline $10-30 \mathrm{~cm} \mathrm{dbh}$ & 17.0 & 65.6 & 39.8 & 23.6 \\
\hline $30-50 \mathrm{~cm} \mathrm{dbh}$ & 45.3 & 16.6 & 23.4 & 62.2 \\
\hline $50-100 \mathrm{~cm} \mathrm{dbh}$ & 75.4 & 0.0 & 8.2 & 32.2 \\
\hline$>100 \mathrm{~cm} \mathrm{dbh}$ & 20.8 & 12.0 & 0.0 & 0.0 \\
\hline Dead trees & 10.2 & 4.7 & 0.1 & 0.5 \\
\hline Total trees & 169.3 & 105.3 & 79.7 & 121.0 \\
\hline \multicolumn{5}{|l|}{ Dead wood } \\
\hline$<0.64 \mathrm{~cm}$ diameter & 0.1 & 0.2 & 0.1 & 0.2 \\
\hline $0.64-2.54 \mathrm{~cm}$ diameter & 1.0 & 1.5 & 0.5 & 0.8 \\
\hline $2.54-7.7 \mathrm{~cm}$ diameter & 6.2 & 6.1 & 0.6 & 0.9 \\
\hline$>7.6 \mathrm{~cm}$ diameter - sound & 11.2 & 9.7 & 1.8 & 12.7 \\
\hline$>7.6 \mathrm{~cm}$ diameter - rotten & 1.4 & 0.0 & 0.2 & 4.0 \\
\hline Total wood & 20.0 & 17.4 & 3.2 & 18.6 \\
\hline Litter/forest floor & $\mathrm{T}$ & $\mathrm{T}$ & $\mathrm{T}$ & $\mathrm{T}$ \\
\hline Seedlings & $\mathrm{T}$ & $\mathrm{T}$ & $\mathrm{T}$ & $\mathrm{T}$ \\
\hline Total aboveground & 189.3 & 122.7 & 83.7 & 139.6 \\
\hline Belowground plant & 145.2 & 80.0 & 43.0 & 60.2 \\
\hline \multicolumn{5}{|l|}{ Soils } \\
\hline $0-10 \mathrm{~cm}$ depth & 53.4 & 62.7 & 16.9 & 28.0 \\
\hline $10-30 \mathrm{~cm}$ depth & 66.1 & 65.4 & 33.9 & 56.5 \\
\hline $30-50 \mathrm{~cm}$ depth & 85.5 & 87.6 & 28.7 & 57.4 \\
\hline $50-100 \mathrm{~cm}$ depth & 206.5 & 199.9 & 71.9 & 156.3 \\
\hline$>100 \mathrm{~cm}$ depth & 320.3 & 105.0 & 287.5 & 761.0 \\
\hline Total belowground & 877.0 & 600.1 & 481.8 & 1119.4 \\
\hline Total ecosystem carbon stock & 1066.3 & 723.3 & 565.5 & 1259.0 \\
\hline $\mathrm{CO}_{2} \mathrm{e}$ of the ecosystem & 3912.0 & 2653.0 & 2074.0 & 4621.0 \\
\hline
\end{tabular}

$\mathrm{dbh}=$ diameter at breast height, $\mathrm{T}=$ trace (signifies the biomass of the component was in low quantities).

Source: Data are from: 1 Kauffman et al. (2011), 2 Donato et al. (2011) and 3 Murdiyarso et al. (2010) 
pools by ecosystem components (figures 4 and 22). Partitioning the ecosystem into components based on forest structure and soil depth is especially important for interpretation of long-term or permanent plots, where objectives include quantifying changes in ecosystem structure and carbon pools through time.
Partitioning ecosystem carbon pools allows for clearer interpretation and more accurate determination of shifts in carbon stocks through time, which may occur due to changes in land management, land use, or climate change (Table 8). It also facilitates reporting of statistical analyses, which can test for
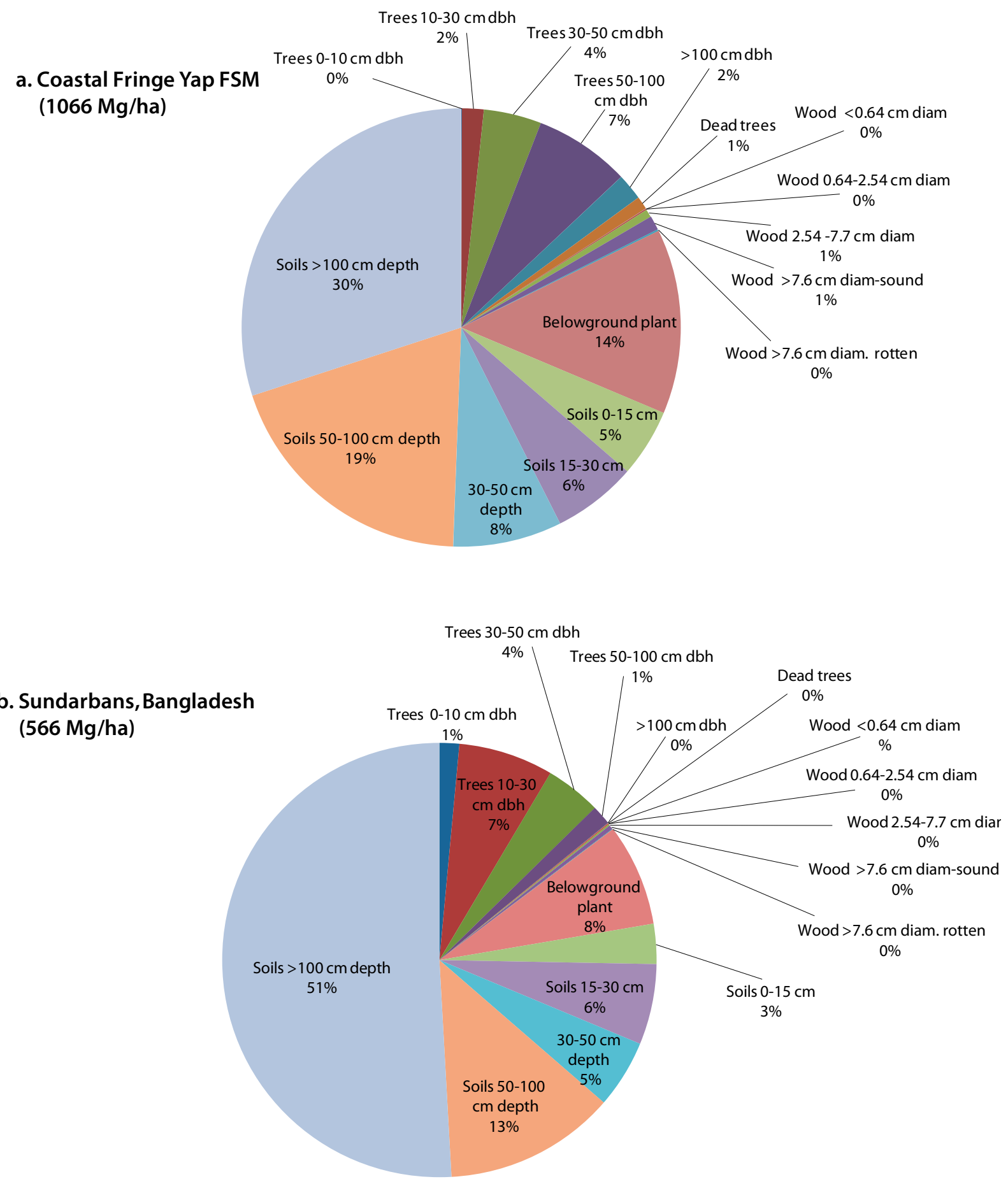
changes in the pool size of individual components, as well as changes in total ecosystem stocks through time.

Graphical displays are useful tools for presenting carbon pools, for example through bar or pie charts
(Figure 22). Photos accompanying carbon stock results may give the reader an idea of how forest composition and structure relates to ecosystem carbon pools (Figure 23). Graphical displays are valuable for rapid interpretation of the size of individual carbon pools and how they compare to
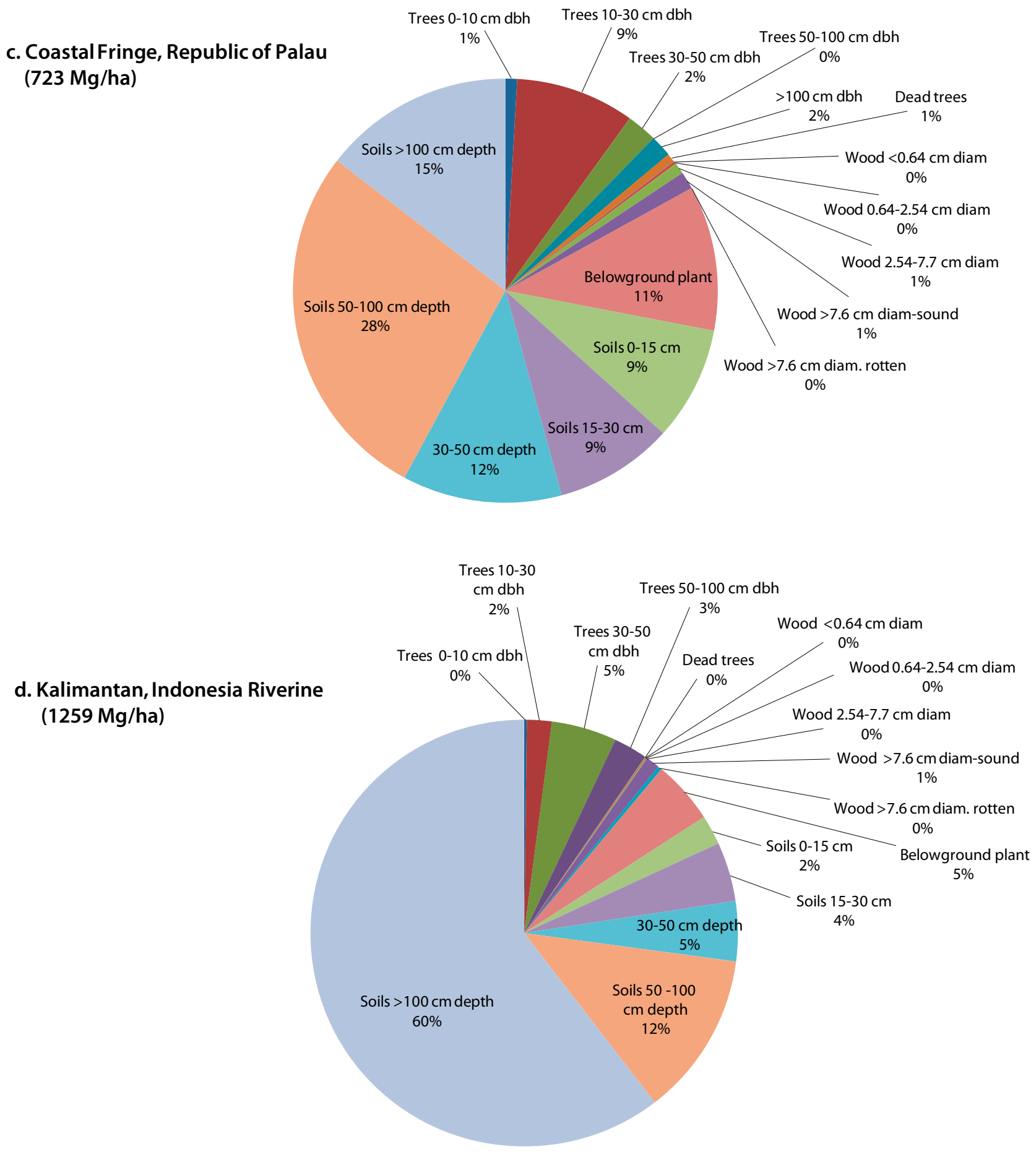

Figure 22. Ecosystem carbon pools of selected mangroves of the Indo-Pacific region.

Source: Kauffman and Cole (2010), Kauffman et al. (2011) and Murdiyarso et al. (2010). FSM is the Federated States of Micronesia, $\mathrm{dbh}$ is the diameter at breast height, diam is the diameter of the dead wood. 

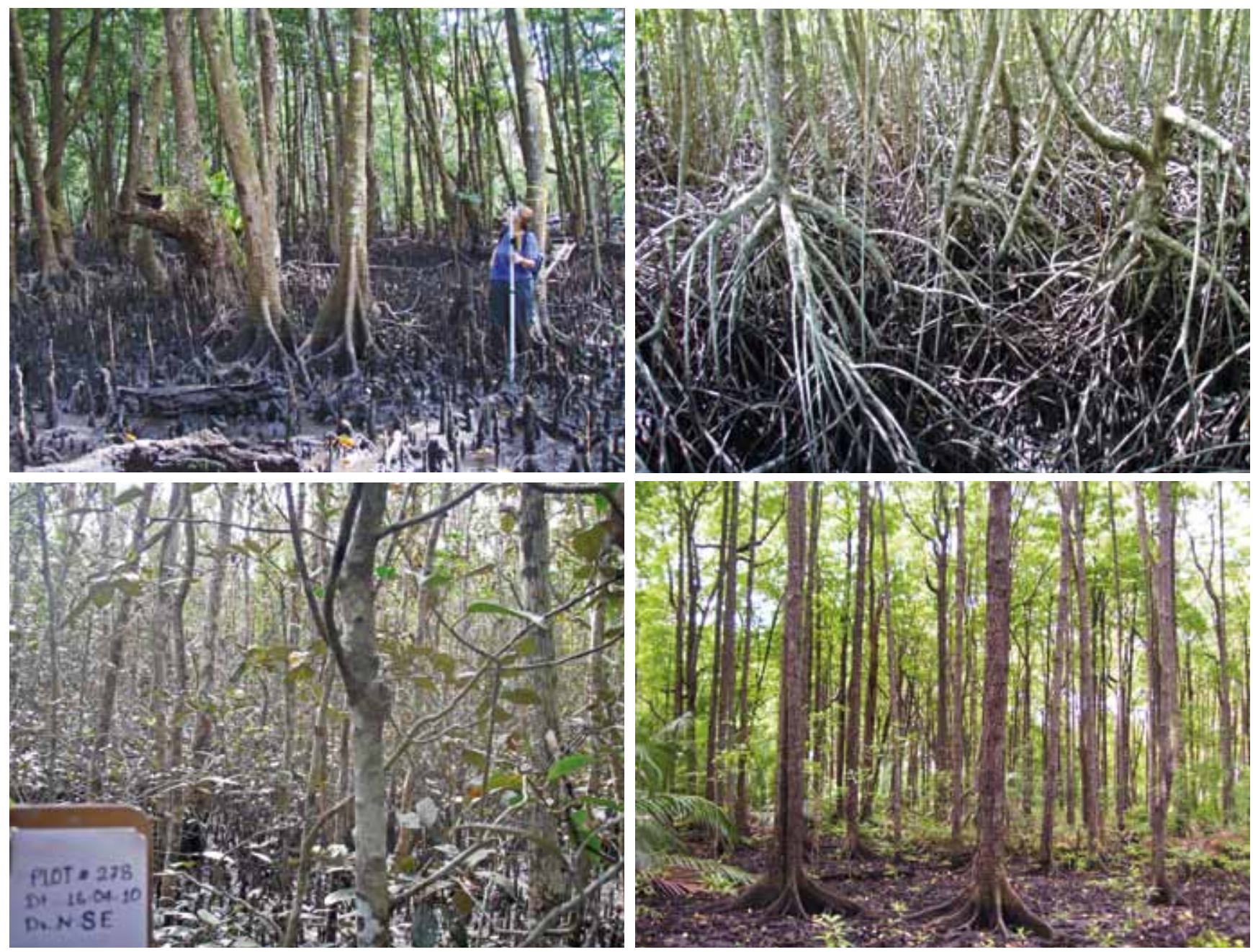

Figure 23. Representative photos of different mangrove forests (Top photos by J.B. Kauffman/Oregon State University; bottom photos by Dan Donato/University of Wisconsin)

Clockwise from upper left: Runuuw, Yap, FSM; Babeldoab, Republic of Palau; the Sundarbans, Bangladesh; and Kalimantan, Indonesia.

other structural components of the ecosystem. They are also valuable in comparing structural differences among different mangroves, or between mangroves and other forest types. For example, Figure 22 makes it clear that belowground carbon pools comprise the majority of the ecosystem stocks while aboveground pools compose about $18 \%$ of the total for fringing mangroves and $11-15 \%$ for riverine mangroves. The figures clearly show that the variation in belowground pools ranging from 482 to $1120 \mathrm{Mg} /$ ha account for the majority of the differences in the total carbon stock among the different mangroves.

Partitioning ecosystem carbon stocks is necessary for comparisons of differing ecosystems and most importantly for determining change over time from permanent plot data. It may be useful to further breakdown the communities on the basis of species. The data in Table 8 demonstrate the variation in both the size and partitioning of ecosystem carbon stocks of mangroves of the Asia-Pacific region. 


\section{References}

Alongi, D.M. 2009 The energetics of mangrove forests. Springer Science and Business Media BV, New York. 216p.

Amira, S. 2008 An estimation of Rhizophora apiculata $\mathrm{Bl}$. biomass in mangrove forest in Batu Ampar Kubu Raya Regency, West Kalimantan. Undergraduate Thesis, Bogor Agricultural University, Indonesia.

Baker, T.R. and Chao, K.J. 2009 Manual for coarse woody debris measurement in RAINFOR plots. University of Leeds, Leeds, UK. http://www. geog.leeds.ac.uk/projects/rainfor/manuals/ CWD_protocol_RAINFOR_2009.pdf (14 December 2011).

Bouillon, S., Borges, A.V., Castaneda-Moya, E., Diele, K., Dittmar, T., Duke N.C., Kristensen, E., Lee, S.Y., Marchand, C., Middelburg, J.J. et al. 2008 Mangrove production and carbon sinks: a revision of global budget estimates. Global Biogeochemical Cycles 22, GB2013. doi:10.1029/2007GB003052.

Brown, J.K. 1971 A planar intersect method for sampling fuel volume and surface area. Forest Science 17: 96-102.

Brown, J.K. and Roussopoulos, P.J. 1974 Eliminating biases in the planar intersect method for estimating volumes of small fuels. Forest Science 20: 350-356.

Burton, A.J. and Pregitzer, K.S. 2008 Measuring forest floor, mineral soil, and root carbon stocks. In: Hoover, C.M. (ed.) Field measurements for forest carbon monitoring. Springer, New York. p. 129-142.

Cahoon, D.R., Henzel, P., Rybczyz, J., McKee, K.L., Proffitt, C.E., Perez, B.C. 2003 Mass tree mortality leads to mangrove peat collapse at Bay Islands, Honduras after Hurricane Mitch. Journal of Ecology 91: 1093-1105.

Cintron, G., Lugo, A.E., Pool, D.J, Morris, G. 1978 Mangroves of arid environments in Puerto Rico and adjacent islands. Biotropica 10: 110-121.

Cintrón, G., Schaeffer-Novelli, Y. 1984. Methods for studying mangrove structures. In The mangrove ecosystem:research methods, ed. S. C. Saenger, and J. G. Snedaker, 91-113. UNESCO Monographs in Oceanographic Methodology 8.

Chave, J., Andalo, C., Brown, S., Cairns, M.A., Chambers, J.Q., Eamus, D., Fölster, H.,
Fromard, F., Higuchi, N., Kira, T. et al. 2005. Tree allometry and improved estimation of carbon stocks and balance in tropical forests. Oecologia 145: 87-99.

Clough, B.F. and Scott, K. 1989 Allometric relationships for estimating above-ground biomass in six mangrove species. Forest Ecology and Management 27: 117-127.

Cole, T.G., Ewel, K., Devoe, N.N. 1999 Structure of mangrove trees and forests in Micronesia. Forest Ecology and Management 117: 95-109.

Coronado-Molina, C., Day, J.W., Reyes, E., Perez B.C. 2004 Standing crop and aboveground biomass partitioning of a dwarf mangrove forest in Taylor River Slough, Florida. Wetlands Ecology and Management 12: 157-164.

Cummings, D.L., Kauffman, J.B., Perry, D.A., Hughes, R.F. 2002 Aboveground biomass and structure of rainforest in the Southwestern Brazilian Amazon. Forest Ecology and Management 163: 293-307.

Dharmawan, I.W.S. and Siregar, C.A. 2008 Soil carbon and carbon estimation of Avicennia marina (Forsk) Vierh in Ciasem, Purwakarta. J Penelitian Hutan dan Konservasi Alam Vol V(4): 317-328.

Donato, D.C., Kauffman, J.B., Stidham, M.A. 2009 Protocols for measuring and reporting carbon stocks in mangrove forests. Unpublished report prepared for the workshops on Global Climate Change and Carbon Financing: Opportunities for Bangladesh. Dhaka, Bangladesh, 28 October-9 November 2009.

Donato, D.C., Kauffman, J.B., Murdiyarso, D., Kurnianto, S., Stidham, M., Kanninen, M. 2011 Mangroves among the most carbon-rich forests in the tropics. Nature Geosciences 4: 293-297.

Duke, N.C., Meynecke, J.O., Dittmann, S, Ellison, A.M., Anger, K., Berger, U., Cannicci, S., Diele, K., Ewel, K.C., Field, C.D., Koedam, N., Lee, S.Y., Marchand, C., Nordhaus, I. DahdouhGuebas, F. 2007 A world without mangroves. Science 317: 41.

Food and Agriculture Organization of the United Nations (FAO) 2007 The world's mangroves 1980-2005. FAO Forestry Paper 153. FAO, Rome. 77p. 
Fromard, F., Puig, H., Mougin, E., Marty, G., Betoulle, J.L., Cadamuro, L. 1998 Structure, above-ground biomass and dynamics of mangrove ecosystems: new data from French Guiana. Oecologia 115: 39-53.

Gerwing, J.J., Schnitzer, S.A., Burnham, R.J., Bongers, F., Chave, J., DeWalt, S.J., Ewango, C.E.N., Foster, R., Kenfack, D., MartínezRamos, M. et al. 2006 A standard protocol for liana censuses. Biotropica 38: 256-261.

Giesen W., Wulffraat, S., Zieren, M., Scholten, L. 2007 Mangrove guidebook for Southeast Asia. Food and Agricultural Organisation and Wetlands International, Bangkok, Thailand. 769p.

Gilman, E., Ellison, J., Duke, N.C., Field, C. 2008 Threats to mangroves from climate change and adaptation options: a review. Aquatic Botany 89: 237-250.

Giri, C., Ochieng, E., Tieszen, L.L., Zhu, Z., Singh, A., Loveland, T., Masek, J., Duke, N. 2011 Status and distribution of mangrove forests of the world using earth observation satellite data. Global Ecology and Biogeography 20: 154-159.

GOFC-GOLD, 2011 A sourcebook of methods and procedures for monitoring and reporting anthropogenic greenhouse gas emissions and removals caused by deforestation, gains and losses of carbon stocks in forests remaining forests, and forestation. GOFC-GOLD Report version COP17-1, GOFC-GOLD Project Office, Natural Resources Canada, Alberta, Canada.

Guild, L.S., Kauffman, J.B., Cohen, W.B., Hlavka, C.B., Ward, D. 2004 Modeling biomass burning emissions from Amazon forest and pastures in Rondonia, Brazil. Ecological Applications 14: 232-236.

Harmon, M.E. and Sexton, J. 1996 Guidelines for measurements of woody detritus in forest ecosystems. US LTER Publication No. 20. US LTER Network Office, University of Washington, College of Forest Resources, Seattle, USA. 73p.

Hidayat, S. and Simpson, W.T. 1994 Use of green moisture content and basic specific gravity to group tropical woods for kiln drying. US Department of Agriculture, Forest Service, Forest Products Laboratory, Madison, USA.

Hooijer, A., Silvius, M., Wösten, H., Page, S. 2006 PEAT-CO ${ }_{2}$ : assessment of $\mathrm{CO}_{2}$ emissions from drained peatlands in SE Asia. Delft Hydraulics report Q3943. Delft Hydraulics, Delft, the Netherlands. 41p

Hughes, R.F., Kauffman, J.B., Jaramillo, V.J. 2000 Ecosystem-scale impacts of deforestation and land use in a humid tropical region of Mexico. Ecological Applications 10: 515-527.

Intergovernmental Panel on Climate Change (IPCC) 2003 Good practice guidance for land use, landuse change, and forestry. Penman, J., Gytarsky, M. Hiraishi, T., Krug, T., Kruger, D., Pipatti, R., Buendia, L., Miwa, K., Ngara, K., Tanabe, K., Wagner, F. (eds.) IPCC, Geneva. http://www. ipcc-nggip.iges.or.jp/public/gpglulucf/gpglulucf. html (13 June 2011).

Intergovernmental Panel on Climate Change (IPCC) 2006 Guidelines, Volume 1 and Volume 4 (Agriculture, forestry, \& other land use), Annex 2 (Summary of equations). IPCC, Geneva. http://www.ipcc-nggip.iges.or.jp/ public/2006gl/vol4.html (13 June 2011).

Intergovernmental Panel on Climate Change (IPCC) 2007 The Fourth Assessment Report: Climate Change 2007. Pachauri, R.K. and Reisinger, A. (eds.) IPCC, Geneva. http://www.ipcc.ch/ publications_and_data/publications_ipcc_ fourth_assessment_report_synthesis_report.htm (13 June 2011).

Jaramillo, V.J., Ahedo-Hernandez, R., Kauffman, J.B. 2003a Root biomass and carbon in a tropical evergreen forest of Mexico: changes with secondary succession and forest conversion to pasture. Journal of Tropical Ecology 19: 457-w464.

Jaramillo, V.J., Kauffman, J.B., Rentería-Rodríguez, L., Cummings, D.L., Ellingson, L.J. 2003b Biomass, carbon, and nitrogen pools in Mexican tropical dry forest landscapes. Ecosystems 6: 609-629.

Kauffman, J.B., Sanford, R.L., Cummings, D.L., Sampaio, E.V.S.B., Salcedo, I.H. 1993 Biomass and nutrient dynamics associated with slash fires in neotropical dry forests. Ecology 74: 140-151.

Kauffman, J.B., Cummings, D.L., Ward, D.E., Babbitt, R. 1995 Fire in the Brazilian Amazon: 1. Biomass, nutrient pools, and losses in slashed primary forests. Oecologia 104: 397-408.

Kauffman, J.B., Cummings, D.L., Ward, D.E. 1998 Fire in the Brazilian Amazon: 2. Biomass, nutrient pools and losses in cattle pastures. Oecologia 113: 415-427. 
Kauffman, J.B., Heider, C., Cole, T., Dwire, K.A., Donato, D.C. 2011 Ecosystem C pools of Micronesian mangrove forests: implications of land use and climate change. Wetlands 31: 343-352.

Kauffman, J.B. and Cole. T. 2010 Micronesian mangrove forest structure and tree response to a severe typhoon. Wetlands 30: 1077-1084.

Komiyama, A., Poungparn, S., Kato, S. 2005 Common allometric equations for estimating the tree weight of mangroves. Journal of Tropical Ecology 21: 471-477.

Komiyama, A., Ong, J.E., Poungparn, S. 2008 Allometry, biomass, and productivity of mangrove forests: A review. Aquatic Botany 89: 128-137.

Laffoley, D.D.A. and Grimsditch, G. 2009 The management of natural coastal carbon sinks. International Union for Conservation of Nature, Gland, Switzerland. 53p.

Langner, A., Miettinen, J., Siegert, F. 2007 Land cover change 2002-2005 in Borneo and the role of fire derived from MODIS imagery. Global Change Biology 13: 2329-2340.

Lu, X.T., Thang, J.W., Feng, Z.L., Li, M.H. 2009 Diversity and aboveground biomass of lianas in the tropical seasonal rain forests of Xishuangbanna, SW China. International Journal of tropical biology 57 (1-2): 211-222.

Mitsch, W.J. and Gosselink, J.G. 2007 Wetlands (Fourth edition). John Wiley and Sons, Inc., New York, USA. 582p.

Mueller-Dombois, D. and Ellenberg, E. 2003 Aims and methods of vegetation ecology. The Blackburn Press. Caldwell New Jersey, USA 547p.

Murdiyarso, D., Donato, D.C., Kauffman, J.B., Stidham, M., Kurnianto, S., Kanninen, M. 2010 Carbon storage in mangrove and peatland ecosystems in Indonesia - A preliminary account from plots in Indonesia. Working paper 48. Center for International Forest Research. Bogor, Indonesia. 35p.

Nellemann, C., Corcoran, E., Durate, C.M., Valdes, L., DeYoung, C., Fonseca, L., Grimditch, G. 2009 Blue Carbon. The role of healthy oceans in binding carbon. United Nations Environment Programme, GRID-Arendal. United Nations Environmental Program. New York, USA. 78p.

Nelson, D.W. and Sommers, L.E. 1996 Total carbon, organic carbon, and organic matter. In: Sparks,
D.L. and Bartels J.M. (eds.) Methods of soil analysis, Part 3, Book Series 5, 961-1010. Soil Science Society of America, Madison, USA.

Page, S.E., Rieley, J.O., Banks, C.J. 2010 Global and regional importance of the tropical peatland carbon pool. Global Change Biology 17: 798-818.

Pearson, T.R.H., Walker, S., Brown, S. 2005 Sourcebook for land use, land-use change and forestry projects. Report from BioCF and Winrock International. http://www.winrock. org/ecosystems/tools.asp?BU=9086 World Bank, Washington DC.

Pearson, T.R.H., Brown, S.L., Birdsey, R.A. 2007 Measurement guidelines for the sequestration of forest carbon. General Technical ReportNRS-18, USDA Forest Service, Northern Research Station Newtown Square, USA.

Putz, F.E. and Chan, H.T. 1986 Tree growth, dynamics, and productivity in a mature mangrove forest in Malaysia. Forest Ecology and Management 17: 211-230.

Robertson, G.P., Coleman, D.C., Bledsoe, C.S., Sollins, P. (eds.) 1999 Standard soil methods for long-term ecological research. Oxford University Press, New York. 462p.

Robertson, A.I. and Daniel, P.A. 1989

Decomposition and the annual flux of detritus from fallen timber in tropical mangrove forests. Limnology and Oceanography 34: 640-646.

Ross, M.S., Ruiz, P.L., Telesnicki, G.J., Meeder, J. 2001 Estimating above-ground biomass and production in mangrove communities of Biscayne National Park, Florida, USA. Wetlands Ecology and Management 9: 27-37.

Saenger, P. 2002 Mangrove ecology, silviculture, and conservation. Kluwer Academic Publishers. Dordrecht, The Netherlands. 360p

Saenger, P. and Snedaker, S.C. 1993 Pantropical trends in mangrove above-ground biomass and annual litterfall. Oecologia 96: 293-299.

Schnitzer, S.A., DeWalt, S.J., Chave, J. 2006 Censuring and measuring lianas: A quantitative comparison of the common methods. Biotropica 38(5): 581-591.

Schumacher, B.A. 2002 Methods for the determination of total organic carbon (TOC) in soils and sediments. NCEA-C- 1282, EMASC-001. US Environmental Protection Agency, Las Vegas, USA. 
Simpson, W.T. 1996 Method to estimate dry-kiln schedules and species groupings: Tropical and temperate hardwoods. RPL-RP-548. USDA Forest Service, Forest Products Laboratory, Madison, USA.

Smith. T.J. and Whelan, K.R.T. 2006 Development of allometric relations for three mangrove species in south Florida for use in the Greater Everglades Ecosystem restoration. Wetlands Ecology and Management 14: 409-419.

Snedaker, S.C. and Lahmann, E.J. 1988 Mangrove understorey absence: a consequence of evolution. Journal of Tropical Biology 4: 311-314.

Soares, M.L.G. and Schaeffer-Novelli, Y. 2005 Above-ground biomass of mangrove species: I. Analysis of models. Estuarine, Coastal and Shelf Science 65: 1-18.

REDD Pilot Program (MRPP), South Sumatra, Indonesia. http://www.merang-redd.org/ REDD/publikasi/category/2-reports.html (13 June 2011).

Sollins, P., Glassman, C., Paul, E.A., Swanston, C., Lajtha, K., Heil, J.W., Elliot, W.T. 1999 Soils carbon and nitrogen: pools and fractions. In: Robertson, G.P., Coleman, D.C., Bledsoe, C.S., Sollins, P. (eds.) Standard soil methods for long-term ecological research, 89-105. Oxford University Press. New York. 462p.

Sparks, D.L. and Bartels, J.M. 1996 Methods of soil analysis. Part 3. Chemical Methods. Soil
Science Society of America, Madison, USA. p. 1125-1131.

Tarlan, M.A. 2008 Biomass estimation of nyirih (Xylocarpus granatum Koenig. 1784) in primary mangrove forest in Batu Ampar, West Kalimantan. Undergraduate thesis, Bogor Agricultural University, Indonesia.

United States Department of Agriculture (USDA) 2008 Field instructions for the annual inventory of California, Oregon and Washington. USDA Forest Service, Forest Inventory and Analysis Program, PNW Research Station. Portland, USA.

Valiela, I., Bowen, J.L., York, J.K. 2001 Mangrove forests: one of the world's threatened major tropical environments. Bioscience 51: 807-815.

van Wagner, C.E. 1968 The line intersect method in forest fuel sampling. Forest Science 24: 469-483.

Waddell, K. L. 2002 Sampling coarse woody debris for multiple attributes in extensive resource inventories. Ecological Indicators 1: 139-153.

Winrock International. 2011 Ecosystem services - tools. Winrock International, Little Rock, USA. www.winrock.org/ecosystems/tools.asp (11 May 2011).

World Agroforestry Centre 2011 Databases. World Agroforestry Centre, Nairobi, Kenya. http:// www.worldagroforestrycentre.org/our_products/ databases (May 11, 2011). 

CIFOR Working Papers contain preliminary or advance research results, significant to tropical forest issues, that need to be published in a timely manner. They are produced to inform and promote discussion. Their content has been internally reviewed but not undergone the lengthier process of external peer review.

This report describes the approaches necessary for the measurement, monitoring and reporting of structure, biomass and carbon stocks in mangrove forests. Mangroves are coastal ecosystems providing numerous ecosystem services affecting both marine and terrestrial resources. In addition, they contain substantial carbon stocks and, due to high rates of deforestation, are significant sources of carbon emissions. Because of their value as carbon stocks and sinks and their numerous other benefits, mangroves could be excellent candidates for carbon mitigation programmes including Reducing Emissions from Deforestation and Forest Degradation, and Enhancing Forest Carbon Stocks in Developing Countries (REDD+). This publication outlines biologically relevant and statistically valid approaches to the efficient and accurate assessment of ecosystem structure, biomass and carbon stocks of mangrove forests. 